\title{
The Phonetics and Phonology of some Syllabic Consonants in Southern British English
}

\author{
Zoë Toft \\ School of Oriental and African Studies \\ University of London
}

\section{$1 \quad$ Introduction}

This article presents new experimental data on the phonetics of syllabic $/ 1 /$ and syllabic $/ \mathrm{n} / \mathrm{in}$ Southern British English and then proposes a new phonological account of their behaviour. Previous analyses (Chomsky and Halle 1968:354, Gimson 1989, Gussmann 1991 and Wells 1995) have proposed that syllabic /l/ and syllabic /n/ should be analysed in a uniform manner. Data presented here, however, shows that syllabic / $/ /$ and syllabic $/ \mathrm{n} /$ behave in very different ways, and in light of this, a unitary analysis is not justified. Instead, a proposal is made that syllabic / $/$ / and syllabic / $\mathrm{n} /$ have different phonological structures, and that these different phonological structures explain their different phonetic behaviours.

This article is organised as follows: First a general background is given to the phenomenon of syllabic consonants both cross linguistically and specifically in Southern British English. In $\S 3$ a set of experiments designed to elicit syllabic consonants are described and in $\$ 4$ the results of these experiments are presented. $\$ 5$ contains a discussion on data published by earlier authors concerning syllabic consonants in English. In $\S 6$ a theoretical phonological framework is set out, and in $\$ 7$ the results of the experiments are analysed in the light of this framework. In the concluding section, some outstanding issues are addressed and several areas for further research are suggested.

\section{$2 \quad$ Background}

In order to discuss syllabic consonants we must clarify what we mean by the term. First we must establish what is meant by 'syllabic', or indeed, 'syllable'. In trying to establish what indeed a syllable is, many phonologists have attempted to describe and explain the possible forms a syllable may take. Typically a syllable is described as consisting of a vocalic centre, optionally accompanied by a consonantal onset or coda, either of which may be complex (cf. Selkirk 1982/1999:329, Blevins 1995:216). In most languages, every syllable has a vowel at its centre. However, some languages allow segments which are not traditionally classed as vocalic to form the nucleus of a syllable, for example the $/ \mathrm{n} / \mathrm{in} / \mathrm{b} \Lambda \mathrm{tn} /$ 'button' or the /l/ in /mıdl/ 'muddle', and it is these segments which are known as syllabic consonants.

One survey (Bell 1978) cites 85 languages with syllabic consonants yet relatively little work has focused on their phonological or phonetic nature. Are syllabic consonants phonetically different from their non-syllabic counterparts? Can syllabic consonants be flanked by (complex) onsets or codas in the same way vocalic nuclei can be? What contextual restrictions are there on syllabic consonants? Answers to such questions will help refine our understanding of what it means to be a syllable. 
(1) Examples of so called syllabic consonants

\begin{tabular}{|c|c|c|c|}
\hline [ejprn] & 'apron' & English & Bloomfield 1933:122 \\
\hline [strrr] & 'stirrer' & English & Bloomfield 1933:122 \\
\hline [ha:bm] or [ha:bən] & 'to have' & German & Clark \&Yallop 1995: 68 \\
\hline [kikn] or [kikən] & 'to look' & NE Dutch varieties & \\
\hline$[\mathrm{m} t \mathrm{tu}]$ & 'man’' & Swahili & Clark \& Yallop 1995:68 \\
\hline [ńlá ] & 'big' & Yoruba & Clark \& Yallop 1995:68 \\
\hline [brno] & 'place name' & Czech & Roach 2000:75 \\
\hline [thp $\left.{ }_{1}^{h} t \chi\right]$ & 'cut it' & Bella Coola & Laver 1994:240 \\
\hline [t àqqakálk ${ }^{\mathrm{h}} \mathrm{t}^{\mathrm{h}}$ ] & 'to close a door' & Nex Perce & Laver 1994:240 \\
\hline$\left[? m_{1}^{3} m_{1}^{3} P^{4}\right]$ & 'you pinch (pl.)' & Quitepec Chinantex & Laver 1994:241 \\
\hline
\end{tabular}

In interpreting these transcriptions we must ask ourselves what do the different authors mean to represent with the syllabicity mark. It quickly becomes apparent that its interpretation varies from author to author, some making no distinction between $ə \mathrm{C}$ and $\mathrm{C}$ or even simply a $\mathrm{C}$ surrounded by less sonorant consonants, either at the phonological level or phonetic level (Houlihan 1973). We are still left asking a number of questions: Are syllabic consonants underlyingly (phonologically) vowel-consonant sequences? Could it instead be the case that (some) syllabic consonants attach directly and uniquely to the syllable nucleus? Do syllabic consonants actually have vowels of some sort associated with them on the surface (phonetically)? If so, are these vowels always present? These questions are important as they relate directly to discussions concerning what can and cannot occur in a nucleus, onset or coda, and thereby to the typology of the syllable. The answers to these questions are also of crucial importance to phonological theories where there are very strict conditions on syllable structure and the presence versus absence of epenthetic vowels. Such a phonological theory will be discussed in $\S 6$.

\subsection{Syllabic consonants in British English}

In British English it is widely recognised that different styles produce different phenomena with respect to syllabic consonants (Roach, Sergeant and Miller 1992). In semi-formal registers /n/, /l/ and /r/ may be syllabic, the latter only in some rhotic dialects. Such syllabics are found in post tonic stress positions and almost always ${ }^{1}$ before a morpheme boundary, for example [bptl] 'bottle' and [bptlin] 'bottling' (Roach 1991:79). Syllabic consonants in semiformal registers are often described as obligatory, in as much as it is deemed to be a mispronunciation to say, for example, [pi:pəl] rather than [pi:pl] for 'people' (Jones 1976:56).

\footnotetext{
${ }^{1}$ It is indeed clear that the vast majority of syllabic consonants in this register are found immediately before a morpheme boundary (either word internally e.g. ,buttoning', or word finally e.g. ,button'). However, there are a small number of cases where a potential syllabic consonant may appear word internally and not at a morpheme boundary. The first set of such cases consists of words such as 'present', 'Arnold', where according to Wells (2000) the $/ \mathrm{n} /$ in the former and the $/ \mathrm{l} /$ in the latter are typically pronounced as syllabic. A pilot study for this paper found that the final stops (i.e. following the potentially syllabic consonants) in these words were virtually always dropped in the register under investigation (potentially a result of the carrier sentence where target words were followed by consonant initial words cf. Cruttenden 1994:261). The second set of cases consists of words ending in [i: ('-y') such as 'history', 'botany', 'chicory' and 'litany'. In these cases it is arguable that the '-y' is a separate morpheme on the grounds of alternations such as 'botany' 'botanic' and thus the potential syllabic consonant is indeed adjacent to a morpheme boundary. However, this still does not help with 'chicory'. A third, disparate set of words is suggested by Rubach (1977:29) and includes 'cabinet', 'definite', 'obsolete'. Even if we accept Rubach's claim that these words contain syllabic consonants (he provides no phonetic evidence, and as we shall see below, syllabic [n] is rarely found after non-coronal consonants), it may be possible to claim that, although the endings '-et', 'ite', '-ete' and '-ute' may no longer be productive derivational morphemes, historically there is a morpheme boundary immediately following the potential syllabic consonant.
} 
In fast and/or casual registers, $/ \mathrm{m} /, / \mathrm{\eta} /$ and even obstruents have been claimed to be syllabic, arising through processes of assimilation and elision. Such syllabics can be found in pre stress positions and domain initially, and their syllabicity is entirely optional. Examples include [spəuz] (Roach, Sergeant and Miller 1992: 476), [probblei] (Sivertsen 1960, quoted in Bell 1978:185), [kju:] (Jones 1959, quoted in Roach, Sergeant and Miller 1992: 476), [f'gp?] (forgot) and [n? 'ma?t]] (not much) (Beaken 1971, quoted in Wells 1982:321). In neither semi-formal, nor fast/casual registers may syllabic consonants be themselves stressed ${ }^{2}$.

In this paper I examine only syllabic $/ \mathrm{n} /$ and $/ \mathrm{l} /$ in semi-formal registers of non rhotic speakers of British English. In the following section I describe a series of experiments designed to investigate whether segments which are transcribed as syllabic consonants ever have vowels (schwas) associated with them, and how syllabic consonants differ from their onset and coda counterparts in terms of duration and formant characteristics.

\section{$3 \quad$ Experiment design}

\subsection{Subjects}

In total the speech of eight subjects was investigated. All subjects were female, native English speakers with a university education reporting normal speech and hearing. All were naïve to the purpose of the experiment.

(2) $\begin{array}{ll}\text { Subject } & \text { Age } \\ 1(\mathrm{EW}) & 26 \\ 2(\mathrm{SH}) & 34 \\ 3(\mathrm{~EB}) & 26 \\ 4(\mathrm{RA}) & 50 \\ 5(\mathrm{RF}) & 24 \\ 6(\mathrm{ES}) & 22 \\ 7(\mathrm{CL}) & 26 \\ 8(\mathrm{JB}) & 31\end{array}$

Linguistic background
Has always lived in South London
First 18 years Birmingham area
First 18 years in Cornwall
First 18 years in Wiltshire
First 18 years in Co. Durham
Has always lived in North London
First 18 years Twickenham
0-9 London, 9-18 Hertfordshire

All subjects other than Nos. 2 and 5 spoke with a modified Southern British English accent showing close systemic similarities to RP English. Subject 2 spoke primarily with a Southern British English accent, although some vowels were monophthised in a manner atypical of Southern British English. Subject 5 spoke with a distinct North Eastern accent ${ }^{3}$. Initially attempts had been made to include only speakers of accents very similar to RP. This however proved impossible and so the only restriction placed on speakers was that they did not vocalize their /l/s as is typical of some English dialects ([bo?u] for 'bottle').

\footnotetext{
${ }^{2}$ Whilst this generalization holds true for most dialects and registers, we may note that some analyses of General American $/ \mathrm{r} /$ argue that $/ \mathrm{r} /$ can be both syllabic and stressed in words such as 'bird' [brd], curt [krt] (Bloomfieldian transcription). We also note the description given by Holder (1972) in Wells (1982:573) of some Guyanese English words which have final stress, including 'bottle' and 'table'.

${ }^{3}$ The results of this speaker at no time differed significantly from the results of other speakers. Thus, although her dialect was not that under main consideration, her results were nevertheless included in the final analysis. That her results did not differ significantly from those results for speakers with RP-type accents suggest that the results of these experiments may be extendable to dialects other than RP, although such a claim would clearly require considerable further research.
} 
Due to circumstances beyond my control not all subjects were used for all parts of the experiment. The results concerning the distribution of syllabic /l/ and syllabic $/ \mathrm{n} /$ following singletons were drawn from subjects $1-6$, as were the results concerning duration and quality of the syllabic consonants versus their non syllabic counterparts. The results for the distribution of syllabic /1/ and syllabic /n/ following clusters were drawn from subjects 2, 3, 7, and 8.

\subsection{Materials}

A list of disyllabic words potentially containing syllabic /l/ or /n/ was drawn up from Wells' (2000) Longman Pronunciation Dictionary, Rockey's (1973) Phonetic Lexicon and an online pronunciation dictionary, Beep ${ }^{4}$. One set of words contained potential syllabic consonants preceded by consonant clusters, whilst a second set of words contained potential syllabic consonants preceded only by singletons. In order to control for contextual effects, potential syllabic consonants were preceded only by $/ \mathrm{p} /, / \mathrm{t} /$, or $/ \mathrm{k} /$ as singletons. Thus words like 'suckle' and 'button' (potential syllabic preceded by $/ \mathrm{p} /, \mathrm{t} /$, or $/ \mathrm{k} /$ singleton) were included whilst words like 'hovel' and 'oven' (potential syllabic preceded by singleton other than $/ \mathrm{p} /, / \mathrm{t} /$, $/ \mathrm{k} /$ ) were not. The consonant clusters in target words were restricted to (homorganic) nasal + (voiced or voiceless) stop clusters. Thus words like 'ankle', 'angle', 'Hendon' and 'Kenton' (potential syllabic preceded by nasal+stop cluster) were included whilst words like 'coastal' and 'silken' (potential syllabic preceded by cluster other than nasal+stop cluster) were not. A list of monosyllabic words containing / $/ /$ and $/ \mathrm{n} /$ in domain initial (onset) and domain final (coda) positions was also drawn up from the same sources. This included words like 'moon' and 'leaf', but not words like 'blue', 'end' or 'elf' (where /l/ and /n/ form part of clusters) ${ }^{5}$. Word frequency was not controlled for (to do so would have resulted in a very restricted set of usable words).

Each target word was place within a carrier sentence ('How does _ translate?') to ensure that all target words occurred in the same prosodic context (i.e. within the word carrying main sentential stress) thus providing some control of durational effects due to syntax, semantics, emphasis and emotion (O'Shaughnessy 1981). The two lists were the combined and the sentence order then quasi-randomised such that sentences containing identical target sequences did not occur adjacent to one another.

\subsection{Procedure}

Each subject was asked to read the list of sentences three times at 'normal conversational tempo' ${ }^{\prime}$. Subjects were recorded onto minidisk in a sound proofed room using a Brüel and Kjær condenser microphone (Type 4165) and measuring amplifier (Type 2609). These recordings were digitised at 22,500 $\mathrm{Hz}$ using Goldwave and then imported in PRAAT where spectrograms for each sentence were produced and labelled. Labelling was done by visual inspection of the waveform and spectrogram, and by listening to the speech signal.

\footnotetext{
${ }^{4} \mathrm{ftp}$ ///svr-ftp.eng.cam.ac.uk/pub/comp.speech/dictionaries/beep.tar.gz

${ }^{5}$ Words ending in /1/ preceded by a high front vowel (e.g. 'feel' or 'pail') were also excluded from this experiment because speakers often lack clear intuitions as to whether such words are monosyllabic or disyllabic. In the latter case, such words could be argued to contain syllabic /1/s. Whilst this is a potentially interesting area of further research it will not be further addressed in this paper.

${ }^{6}$ No specific measures were taken to control for inter-speaker tempo variation
} 
The segmentation guidelines were as follows: Fricative-sonorant boundaries (e.g. [hav dəz lif...]) were established at the offset of frication noise and the onset of higher amplitude components in the periodic part of the signal. Vowel-sonorant (e.g. [berkən]) boundaries were established by reference to discontinuities in the amplitude of the higher frequency components of the periodic signal, formant transitions and the presence of spectral zeros. Stop-sonorant and stop-vowel boundaries (e.g. [bptl] or [beIkən]) were established with reference to onset and offset of voicing, and the presence of higher amplitude components in the periodic part of the signal. Thus aspiration after the stop release was not included in the vowel (or sonorant) duration (contra Umeda 1976).

As can be seen in (3), a target consonant was labelled as syllabic if there was no evidence, either in the waveform or in the spectrogram, of a vowel of any sort. If there were visual cues to the presence of a vowel, as in (4), the target consonant was labelled 'post schwa'. In total 1705 sentences were recorded and labelled (some tokens were discarded due to noise interference on the recording e.g. speaker coughing or page turning). Duration and formant measurements were extracted ${ }^{7}$ and all results were analysed using SPSS, where the threshold of significance was set at $95 \%$.

(3) An example of labelling a syllabic consonant: 'beaten' [bi:tn] ${ }^{8}$

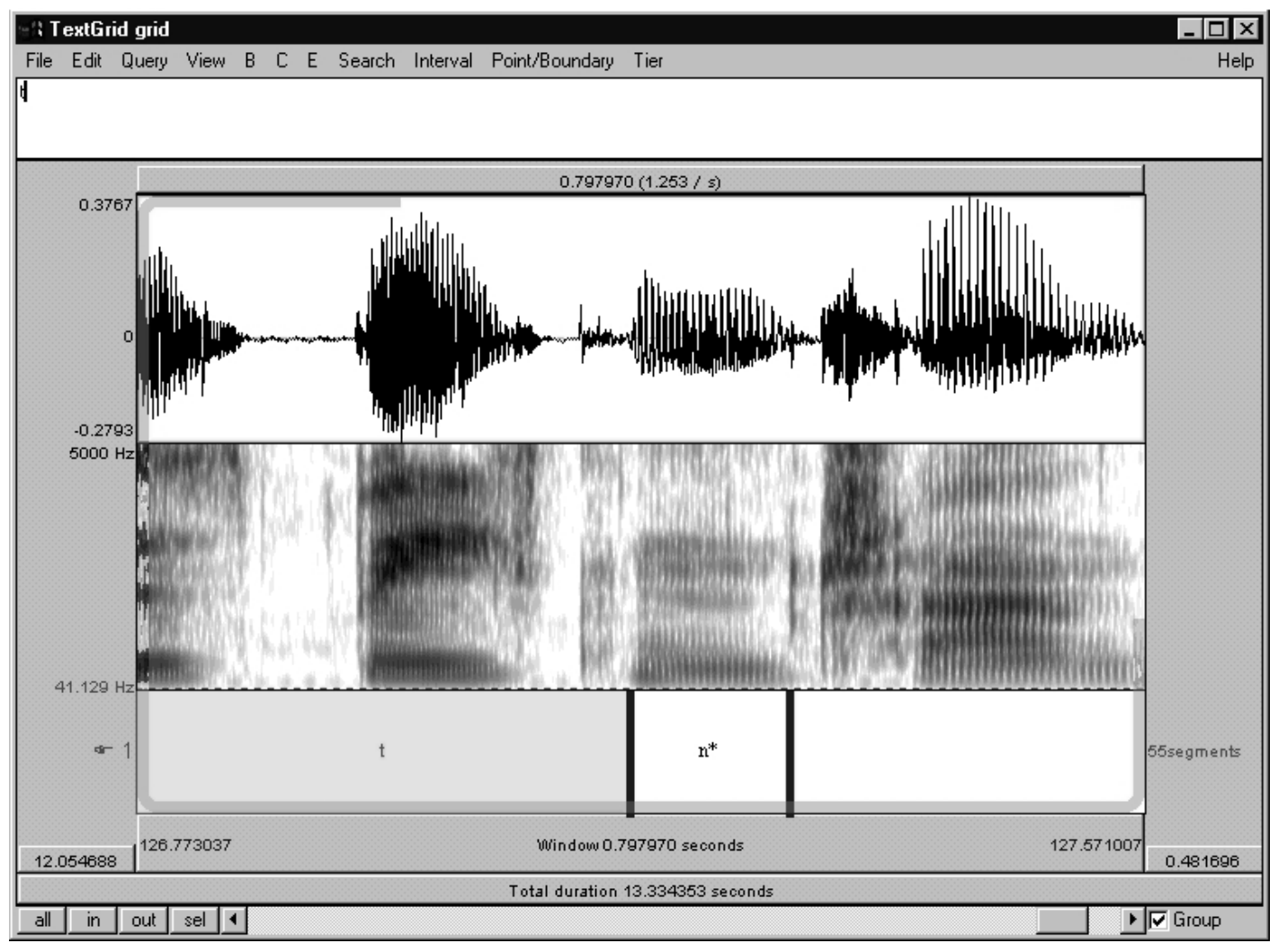

\footnotetext{
${ }^{7}$ Data was extracted using a PRAAT script. A random sample of these results were checked by hand and found to be accurate.

${ }^{8}$ ' $\mathrm{C}^{* \prime}$ was my label for a syllabic consonant. Thus $\mathrm{n}^{*}=[\mathrm{n}]$. 'C1' was my label for a post schwa consonant. Thus $\mathrm{n} 1=[\mathrm{n}]$. The onset of the preceding consonant is not marked.
} 
(4) An example of labelling a non syllabic consonant: 'spoken' [spəukən]

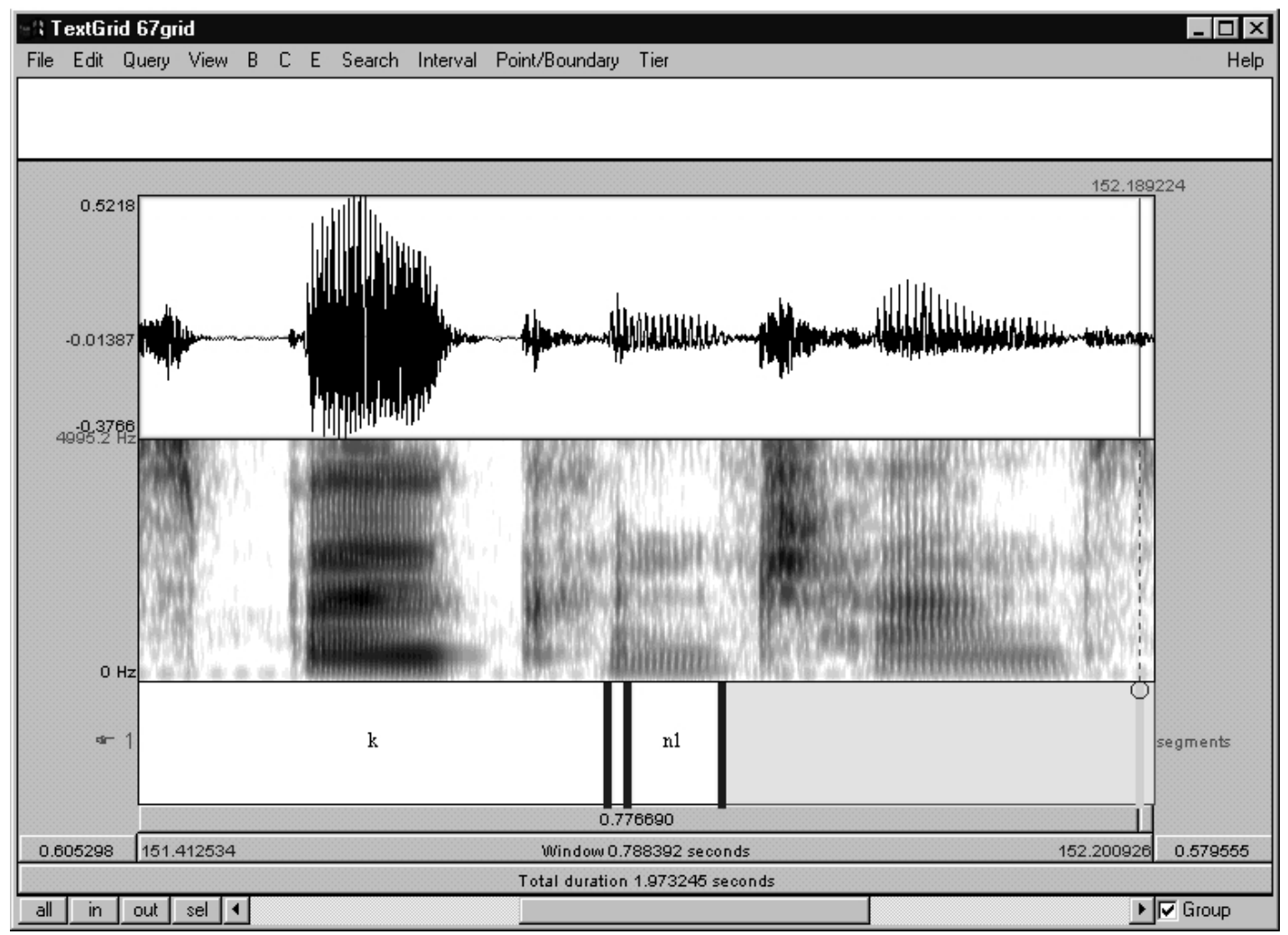

\section{$4 \quad$ Experimental results}

\subsection{Results concerning distributional data}

With regard to the distribution of syllabic /1/ and syllabic /n/ post singletons, both visual inspection and the results of statistical tests ${ }^{9}$ confirmed that /1/ was found to be syllabic irrespective of context, whilst the distribution of syllabic $/ \mathrm{n} /$ was context dependent, being found primarily only after $/ \mathrm{t} /$, and not after $/ \mathrm{p} /$ or $/ \mathrm{k} /$.

(5) Distribution of syllabic /l/ after /p/, /t/ and /k/, based on data from subjects 1-6

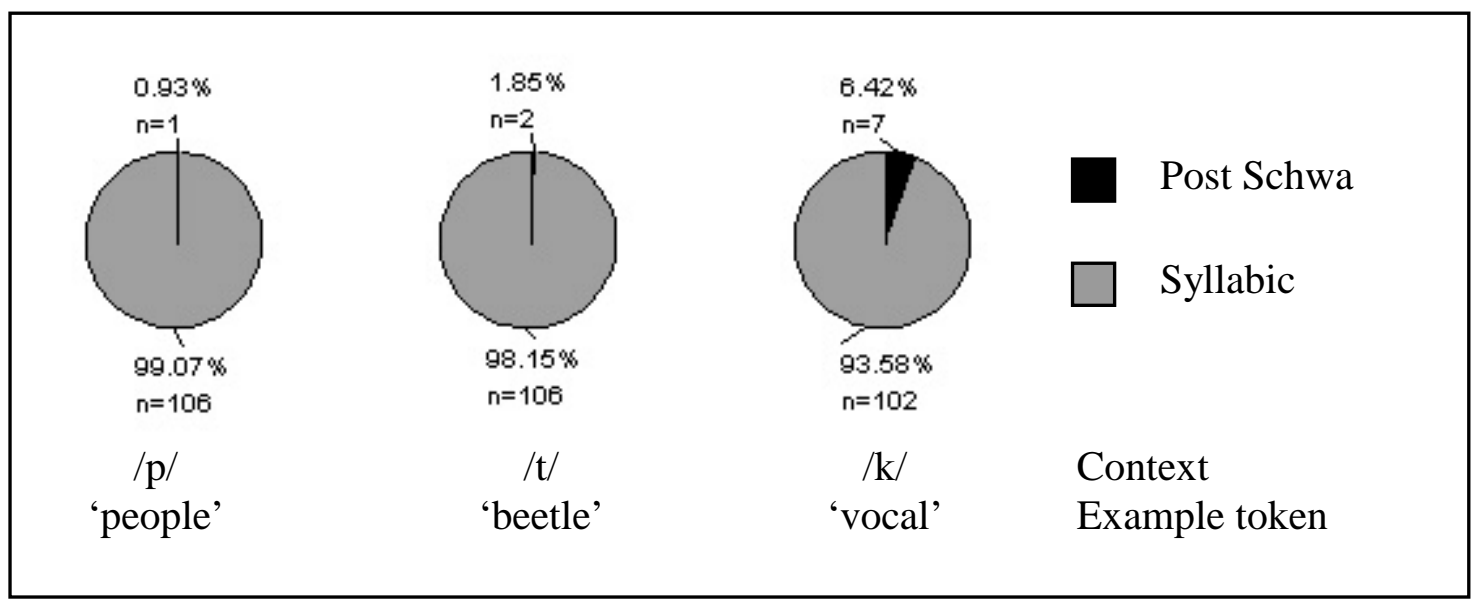

\footnotetext{
${ }^{9}$ For discussion of the tests used see Woods, Fletcher and Hughes (1986) and Rietveld and van Hout (1993).
} 
The figures in (5) suggest that the distribution of syllabic /1/ is not random and a binomial statistic confirms that all distributions of syllabic /1/ deviate significantly from chance $(\mathrm{p}<0.001)$. Statistically there appear to be just significant differences between the three contexts, $/ \mathrm{p} /, / \mathrm{t} /$ and $/ \mathrm{k} /\left(\chi^{2}(2)=6.261, \mathrm{p}=0.044\right)$. However, this chi-squared was obtained from a table where $50 \%$ of the cells have an expected count less than 5 . As a consequence the value obtained for $\mathrm{p}$ may be inaccurately low and therefore what appears to be just significant is actually unlikely to be so.

(6) Distribution of syllabic $/ \mathrm{n} /$ after $/ \mathrm{p} /$, /t/ and $/ \mathrm{k} /$, based on data from subjects 1-6

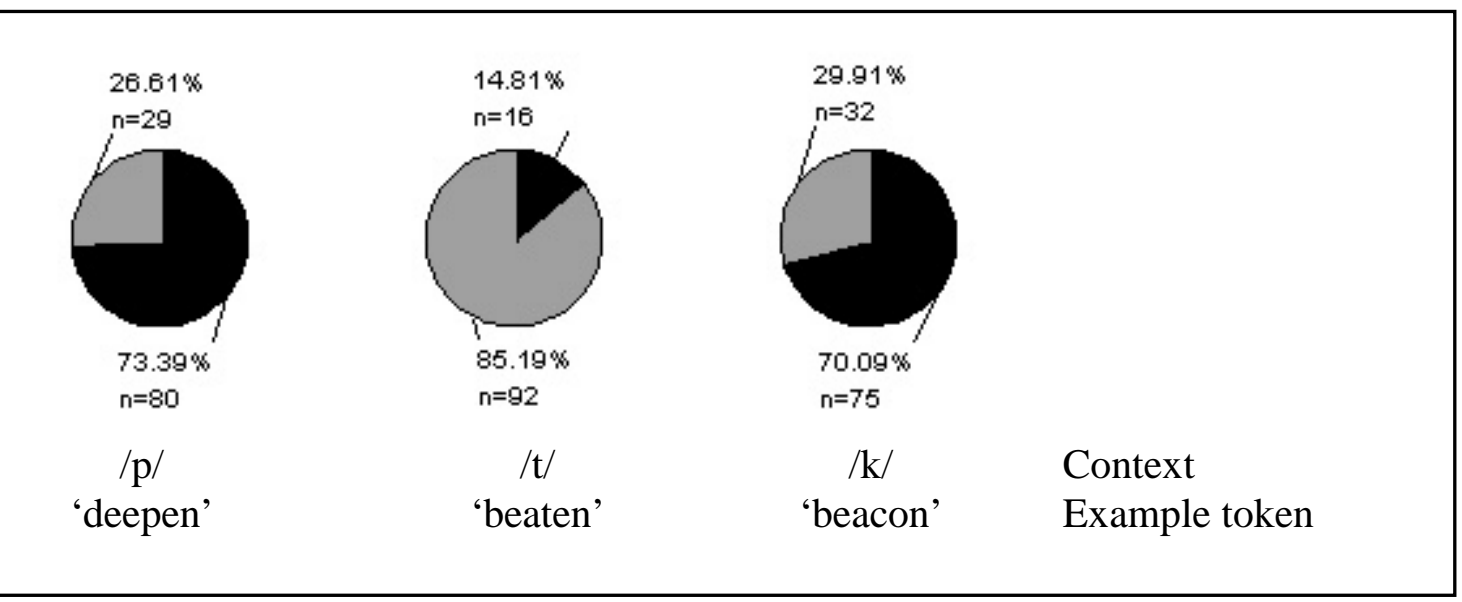

The figures in (6) suggest that the distribution of syllabic $/ \mathrm{n} /$ is not random, and a binomial statistic confirms that all distributions of syllabic $/ \mathrm{n} /$ deviate significantly from chance $(\mathrm{p}<0.001)$. Statistically there are highly significant differences between the three contexts $\left(\chi^{2}\right.$ $(2)=93.914, p<0.001)$ and the pie chart patterns suggest that $/ \mathrm{n} /$ tends to be syllabic following /t/ and non-syllabic following $/ \mathrm{p} /$ and $/ \mathrm{k} /$.

These results show the first difference in behaviour between syllabic /1/ and syllabic $/ \mathrm{n} /$, by suggesting that place of context influences distribution of syllabic $/ \mathrm{n} / \mathrm{but}$ not of syllabic /l/. /l/ appears to be always syllabic when it is preceded by any consonant and followed by a word boundary, whilst $/ \mathrm{n} /$ must be preceded by a coronal consonant to be syllabic ${ }^{10,11}$.

These results were supported by data from a pilot study (642 sentences) based on speaker 1 with an expanded set of contexts $(/ p, t, k, b, d, g, s, z, f, v /)$ :

\footnotetext{
${ }^{10}$ It must be acknowledged that my results are statistical rather than categorical. Thus, for example, not all potential syllabic /n/s preceded by (homorganic) /t/ were actually realized as syllabic. One factor that may play a role in the realization of target consonants as syllabic is their relative frequency: it has been shown (Fidelholtz 1975) that relative frequency can significantly influence vowel reduction (the more frequent a word, the more likely it is to show vowel reduction). This being the case, it may be demonstrable that frequency also plays a role in total vowel absence, in other words, in the distribution of syllabic consonants. As reported in $\S 3$ word frequency was not controlled for in this set of experiments.

${ }^{11}$ As (6) shows, /n/ is syllabic approximately $25 \%$ of the time when preceded by /p/ or $/ \mathrm{k} /$. Readers might be tempted to speculate that these cases actually represent instances of assimilation i.e. [pm] instead of [pn], and $[\mathrm{kn}]$ instead of [kn]. However, this potentiality was borne in mind when labelling and care was taken to listen to the precise quality of the nasal and to label it accordingly. Thus the figures in (6) should be interpreted as representing cases of syllabic and non syllabic /n/ only: no cases of assimilation were found, which is perhaps not surprising given the relative formality of the recording environment and the standard descriptions that assimilation is more likely to occur in fast and casual speech than in formal speech (Roach, Sergeant and Miller 1992).
} 
(7) Place: Distribution of syllabic /1/ after expanded set of contexts, classified by place of articulation (subject 1)

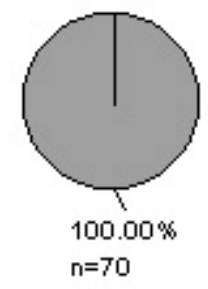

labial

'bauble'

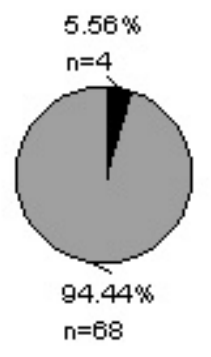

coronal 'sozzle'

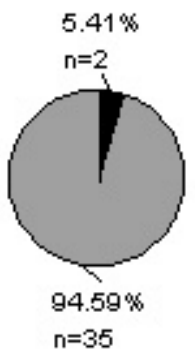

velar 'beagle'
Post Schwa

Syllabic

\section{Context}

Example token

With this expanded set of contexts we see that there is no statistically significant effect of place on the occurrence of syllabic $/ 1 /\left(\chi^{2}(2)=3.99 \mathrm{p}=0.14\right)$. Again, this chi-squared was obtained from a table where $50 \%$ of the cells had an expected count less than 5 , and thus it is likely that the value of $\mathrm{p}$ is inaccurately low.

Turning to (8), below, again the data from this pilot study with an expanded set of contexts supports the conclusions reached on the basis of a restricted set of contexts. There is a highly statistically significant effect of place on the occurrence of syllabic $/ \mathrm{n} /\left(\chi^{2}(2)=\right.$ $138.59, \mathrm{p}<0.001)$ and the pie chart patterns show that it is primarily after homorganic i.e. coronal consonants that syllabic $/ \mathrm{n} /$ is found.

(8) Place: Distribution of syllabic / $\mathrm{n} /$ after expanded set of contexts, classified by place of articulation (subject 1)

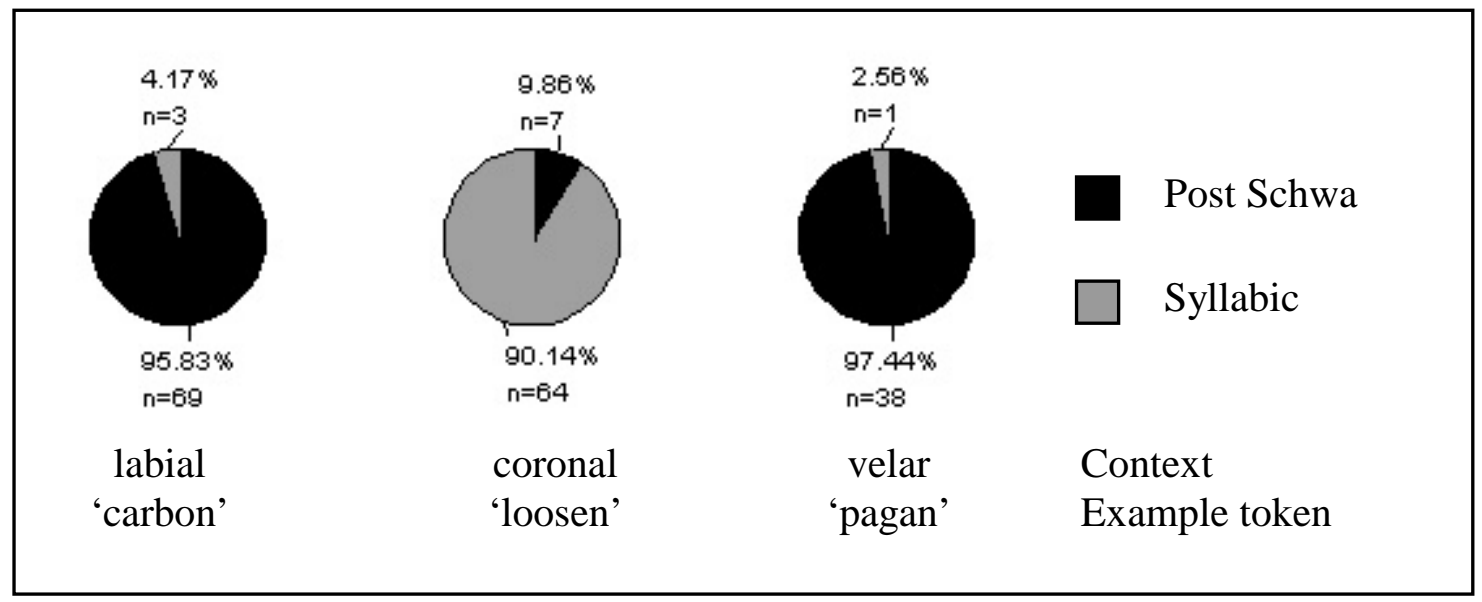

A second asymmetry in the behaviour of syllabic / $/ /$ and syllabic /n/ is evident in their distribution following nasal+stop clusters. Both visual inspection and the results of statistical tests confirmed that $/ \mathrm{l} /$ was found to be syllabic irrespective of context, whilst $/ \mathrm{n} /$ was found never to be syllabic, not even when preceded by a /nt/, i.e. homorganic cluster. 
(9) Distribution of syllabic /1/ after nasal+stop clusters (subjects 2, 3, 7, 8)

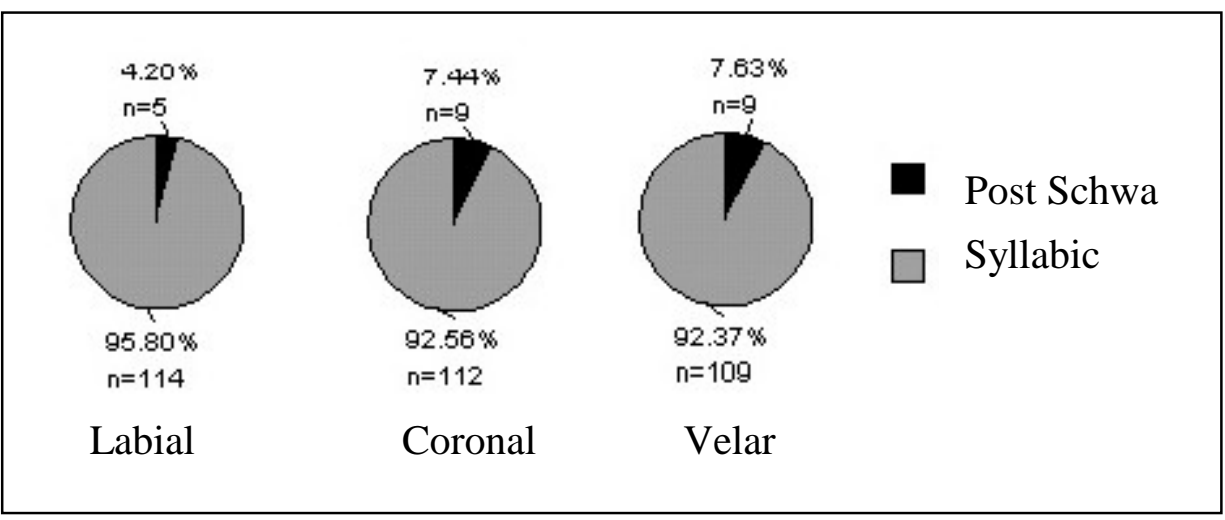

A binomial statistic shows that all distributions deviate significantly from chance $(\mathrm{p}<0.001)$. For target consonant $/ 1 /$ there are not significant differences between the three contexts $\left(\chi^{2}(2)\right.$ $=1.469, \mathrm{p}=0.480$ ).

(10) Distribution of syllabic /n/ after nasal+stop clusters

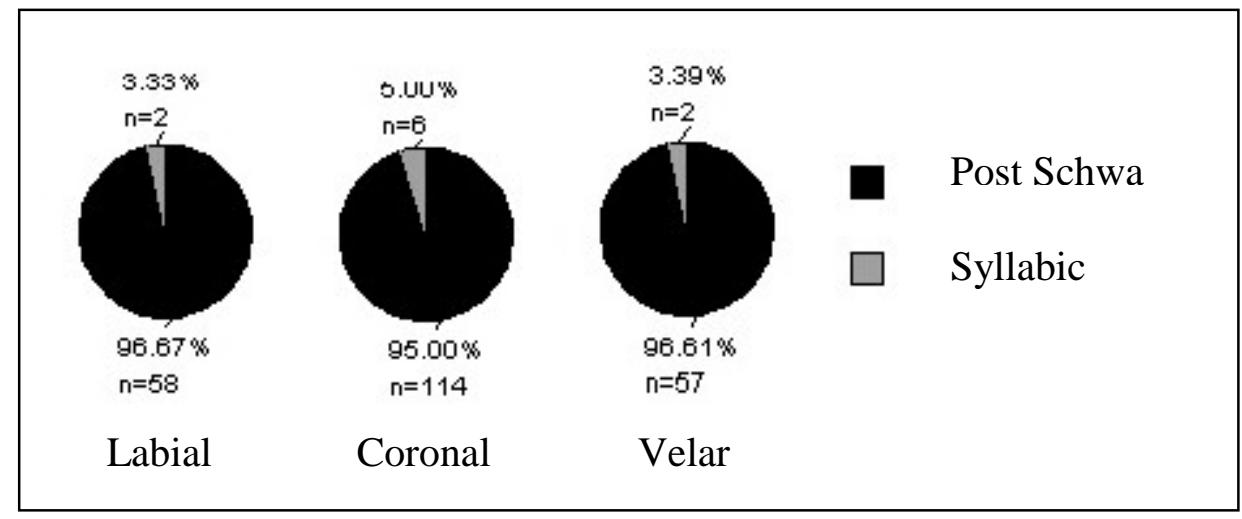

Again, for target consonant $/ \mathrm{n} /$, a binomial statistic shows that all distributions deviate significantly from chance $(\mathrm{p}<0.001)$ and that there are no significant differences between the three contexts $\left(\chi^{2}(2)=0.400, \mathrm{p}=0.819\right)$. This $\mathrm{p}$ may in fact be inaccurately low given that $33.3 \%$ of cells had expected counts of less than 5 .

To conclude this section, if we consider and compare the results concerning the distribution of syllabic / / / and syllabic /n/ following both singletons and clusters as presented in (5), (6), (9) and (10) we note two different patterns of behaviour. When a potential syllabic consonant is preceded by a singleton, context in the form of place of articulation, does affect the distribution of syllabic $/ \mathrm{n} /: / \mathrm{n} /$ will be syllabic if the context is coronal. The distribution of syllabic $/ 1 /$, however, is not influenced by place of context. When a potential syllabic consonant is preceded by a (nasal+stop) cluster we see a different pattern of behaviour: $/ \mathrm{n} / \mathrm{is}$ never syllabic, not even when preceded by a coronal cluster, whilst/1/ continues to be syllabic irrespective of context. 


\subsection{Continuous data results: durations and formant characteristics}

In this section I first present data regarding the mean duration and mean formant values for four different /1/ allophones: onset (word initial), coda (word final), syllabic and post schwa. We see that with regard to duration, coda /1/ is distinct from all other allophones, being significantly longer. With regard to formant values we see that onset /l/ is distinct from all other allophones, having a significantly lower $F_{1}$ and higher $F_{2}$.

In the second set of data we see that $/ \mathrm{n} /$ allophones do not pattern like /1/ allophones with respect to duration: onset $/ \mathrm{n} /$ is significantly shorter than all other allophones. Formant values for $/ \mathrm{n} /$ allophones were not investigated; there are no major differences in articulation for the different allophones and nasal formants are highly variable from one speaker to the next because of anatomical differences (Stevens 1998). Given this, any formant data gathered would be difficult to meaningfully analyse.

\subsubsection{Results for $/ / /$}

(11) Summary of continuous data for /// based on subjects 1-6: Means (standard deviations)

\begin{tabular}{|c|c|c|c|c|}
\hline & $\begin{array}{c}\text { Syllabic } \\
(\mathrm{N}=314)\end{array}$ & $\begin{array}{c}\text { Post Schwa } \\
(\mathrm{N}=10)\end{array}$ & $\begin{array}{c}\text { Onset } \\
(\mathrm{N}=114)\end{array}$ & $\begin{array}{c}\text { Coda } \\
(\mathrm{N}=116)\end{array}$ \\
\hline Duration (ms) & $86(18)$ & $70(17)$ & $81(17)$ & $116(27)$ \\
\hline $\mathrm{F}_{1}(\text { Bark })^{12}$ & $4.62(0.45)$ & $4.52(0.36)$ & $3.90(0.32)$ & $4.41(0.59)$ \\
\hline $\mathrm{F}_{2}$ (Bark) & $9.03(0.85)$ & $8.82(0.41)$ & $11.13(0.71)$ & $8.76(1.46)$ \\
\hline
\end{tabular}

NB. $\mathrm{N}=$ number of tokens

In (11) there appear to be differences in mean duration of the different /1/ allophones. A (one way) ANOVA test confirms that there is an effect of target $C$ allophone on mean duration, ( $\mathrm{F}$ $(3,550)=79.70, \mathrm{p}<0.001)$. A Tukey post hoc test shows that the duration of coda $/ \mathrm{l} / \mathrm{is}$ significantly longer than syllabic /1/, post schwa /1/ and onset /1/ $(\mathrm{p}<0.001$ in each case).

\footnotetext{
12 All frequency measures are given in Bark (not Hz). The bark scale is perceptually more real than the Hz scale, and I have chosen to use it as I believe auditory perception to be at the heart of phonology (cf. Harris 2000).
} 
(12) Mean duration (in seconds) of /1/ allophones based on subjects 1-6

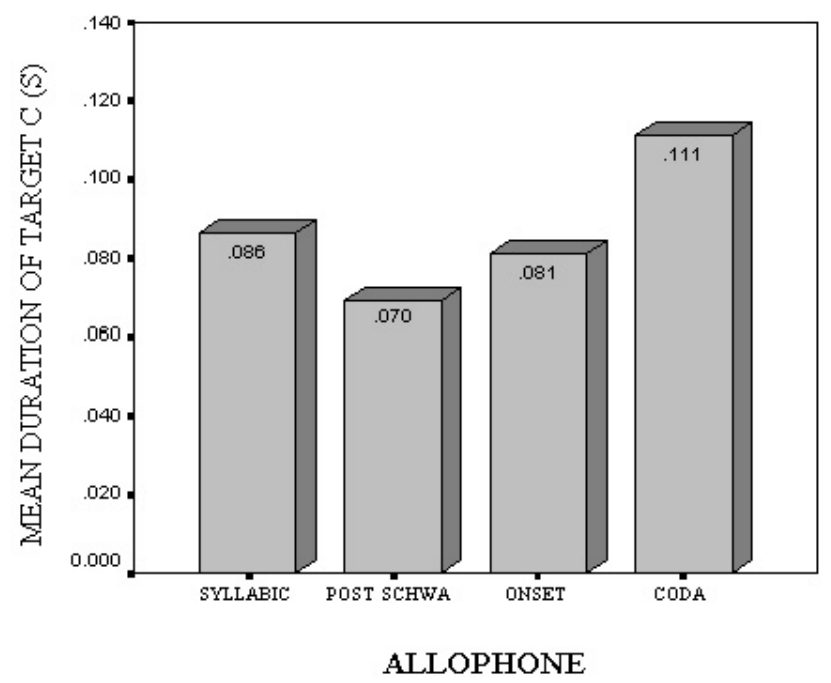

A Tukey post hoc test also shows that the duration of syllabic /1/ is significantly longer than post schwa /1/ ( $\mathrm{p}=0.045)$. However, none of the other durational differences are significant.

If we now consider the formant characteristics of the four /l/ allophones, there appear to be differences in the means of both $\mathrm{F}_{1}$ and $\mathrm{F}_{2}$. An ANOVA test confirms that there is an effect of target $C$ allophone on mean formant values $(\mathrm{F}(3,550)=69.13, \mathrm{p}<0.001)$. Tukey post hoc tests show that the $F_{1}$ of onset $/ 1$ / is significantly lower, and the $F_{2}$ of onset $/ 1 /$ is significantly higher than those of the other allophones ( $<<0.001$ in each case). In other words, onset /1/ can be characterised as 'light' or 'clear', whilst coda /1/, syllabic /1/ and post schwa /1/ are 'dark', or velarized ${ }^{13}$, as can be seen in (13).

(13) A plot of $F_{1}$ against $F_{2}$ for /1/ allophones based on subjects 1-6

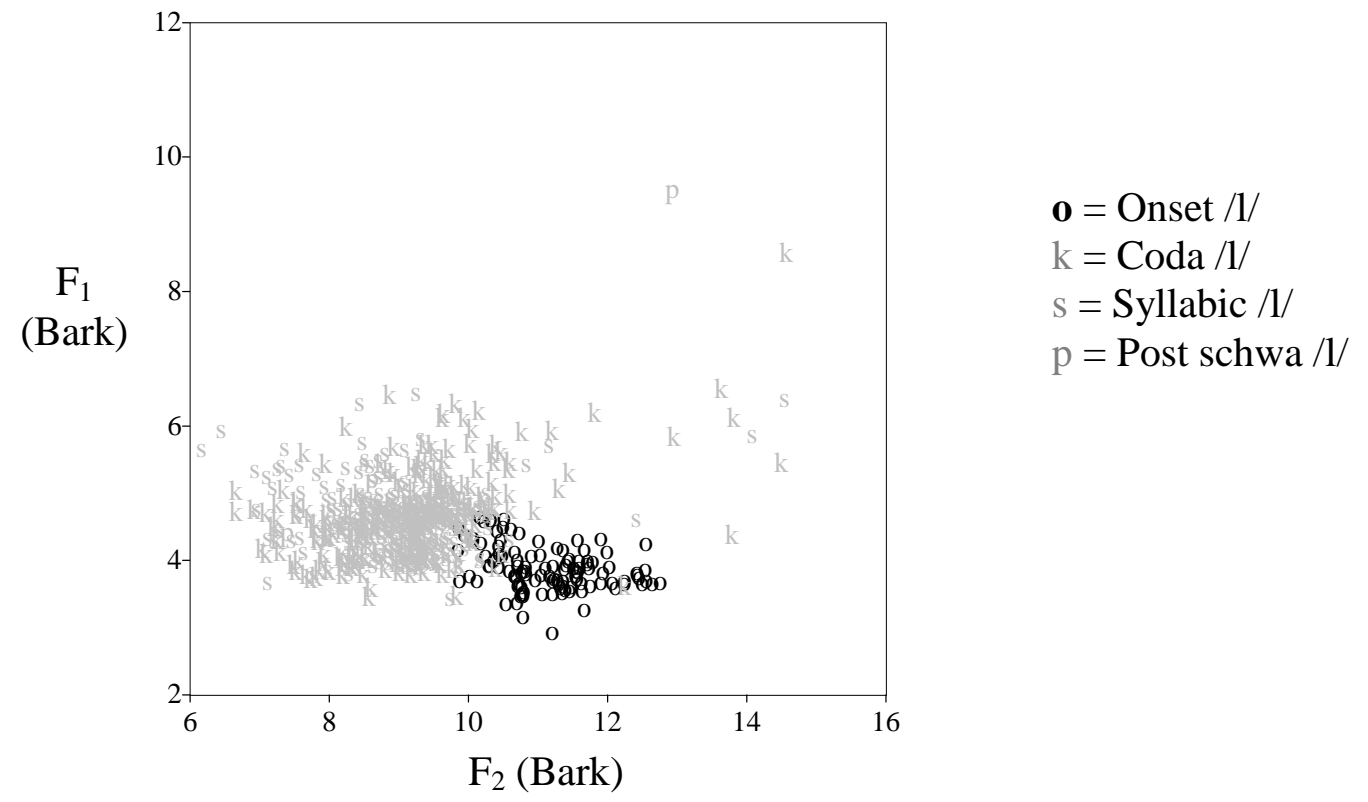

\footnotetext{
${ }^{13}$ Quite what articulation gives rise to this acoustic quality is a matter of debate. See Cruttenden (1994) and Sproat and Fujimura (1993) for differing views.
} 


\subsubsection{Results for $/ \mathbf{n} /$}

(14) Summary of durational data for $/ \mathrm{n} /$ based on subjects 1-6: Means (standard deviations)

\begin{tabular}{|l|l|l|l|l|}
\hline & $\begin{array}{l}\text { Syllabic } \\
(\mathrm{N}=153)\end{array}$ & $\begin{array}{l}\text { Post Schwa } \\
(\mathrm{N}=171)\end{array}$ & $\begin{array}{l}\text { Onset } \\
(\mathrm{N}=116)\end{array}$ & $\begin{array}{l}\text { Coda } \\
(\mathrm{N}=114)\end{array}$ \\
\hline Duration (ms) & $106(20)$ & $98(18)$ & $86(24)$ & $102(22)$ \\
\hline
\end{tabular}

NB. $\mathrm{N}=$ number of tokens

An ANOVA test shows that there is an effect of target $C$ allophone on the mean duration of the four $/ \mathrm{n} /$ allophones $(\mathrm{F}(3,550) 21.92, \mathrm{p}<0.001)$ and a Tukey post hoc test shows that the duration of onset $/ \mathrm{n} /$ is significantly shorter than that of syllabic $/ \mathrm{n} /$, post schwa $/ \mathrm{n} /$ and coda $/ \mathrm{n} /(\mathrm{p}<0.001$ in all cases). Onset $/ \mathrm{n} /$ is on average $16 \mathrm{~ms}$ shorter than the other allophones of $/ \mathrm{n} /$ as can be seen in the graph below.

(15) Mean duration of $/ \mathrm{n} /$ allophones based on subjects 1-6

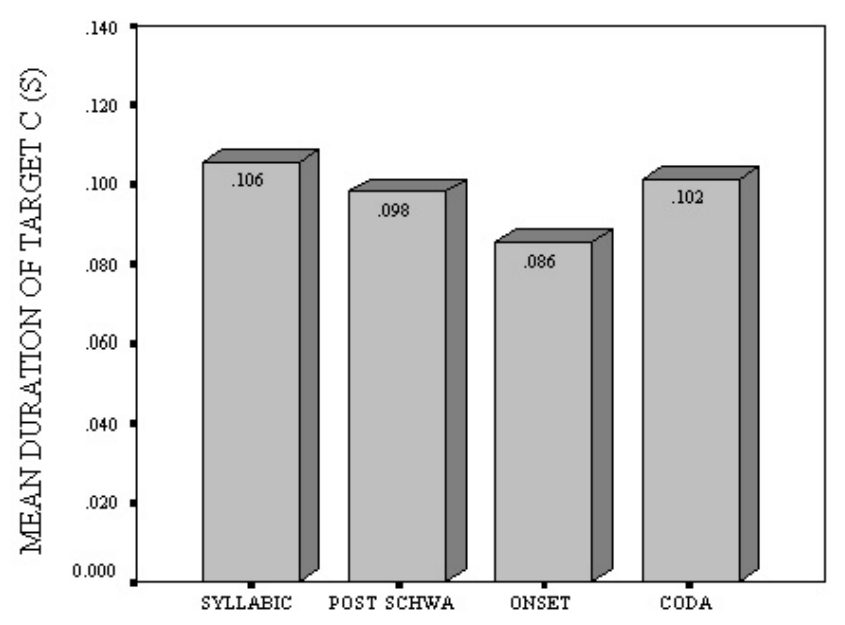

ALLOPHONE

A Tukey post hoc test also shows that the duration of syllabic $/ \mathrm{n} /$ is significantly longer than the duration of post schwa $/ \mathrm{n} /(\mathrm{p}=0.006)$, though none of the other differences in duration are significant.

To summarise and conclude $\S 4$, what we have seen above is three ways in which syllabic /n/ behaves differently from syllabic /l/: (i) Distribution of syllabic $/ \mathrm{n} /$, but not syllabic / $/$ is sensitive to the context's place of articulation; (ii) Distribution of syllabic $/ \mathrm{n} /$, but not syllabic /l/ is sensitive to the context's structural complexity i.e. whether or not it is preceded by a singleton or a cluster; (iii) The duration of syllabic $/ \mathrm{n} /$ is not significantly different from the duration of coda $/ \mathrm{n} /$ whilst it is significantly different from the duration of onset $/ \mathrm{n} /$. Syllabic $/ \mathrm{l} /$, on the other hand, is not significantly different from onset /1/ with 
respect to duration, yet it is significantly different from coda /1/. Thus syllabic /1/ displays a mirror image pattern with respect to syllabic $/ \mathrm{n} /$.

\section{Discussion of phonetic data}

In this section I present data published by earlier authors on the durational and formant characteristics of different allophones of English /l/ and /n/ by way of comparison with my data above. This will lead to a discussion of the phonological value of durational and formant cues and the relationship more generally between continuous phonetic data and categorical phonological structures.

The following data is taken from Barry (2000), Byrd (1993), Lehiste (1964), Sproat and Fujimura (1993) and Umeda (1976) ${ }^{14}$. Data presented above in (11) and (14) is also included here for convenience.

(16) A comparison of /l/ allophone formant values: $F_{1}$ and $F_{2}{ }^{15}$

\begin{tabular}{|l|l|l|l|l|}
\hline & Author & Syllabic & Onset & Coda \\
\hline \multirow{3}{*}{$\mathrm{F}_{1}$ (Bark) } & Toft & 4.62 & 3.90 & 4.41 \\
\cline { 2 - 5 } & Lehiste & 4.35 & 3.08 & 4.57 \\
\cline { 2 - 5 } & Barry & - & - & - \\
\hline \multirow{3}{*}{$\mathrm{F}_{2}$ (Bark) } & Toft & 9.03 & 11.13 & 8.76 \\
\cline { 2 - 5 } & Lehiste & 7.15 & 8.21 & 7.21 \\
\cline { 2 - 5 } & Barry & 8.00 & 9.92 & 8.33 \\
\hline
\end{tabular}

(17) A comparison of $/ 1 /$ allophone formant values: $F_{2}-F_{1}{ }^{16}$

\begin{tabular}{|l|l|l|l|l|}
\hline & Author & Syllabic & Onset & Coda \\
\hline $\mathrm{F}_{2}-\mathrm{F}_{1}($ Hertz) & Toft & 630 & 1146 & 606 \\
\cline { 2 - 5 } & Lehiste & 355 & 655 & 340 \\
\cline { 2 - 5 } & $\begin{array}{l}\text { Sproat \& } \\
\text { Fujimura }\end{array}$ & - & 1077 & 657 \\
\hline
\end{tabular}

\footnotetext{
${ }^{14}$ The experiments from which data has been drawn varied in their scope and aims and thus are not directly comparable with my own data: data collection conditions (e.g. stimuli, speaker sex and number) vary from paper to paper. Barry (2000) is based on acoustic and articulatory (EPG) data from 3 speakers of RP English for formant data and 2 speakers for duration data. Their sex is not specified. Byrd (1993) is based on acoustic data drawn from the TIMIT corpus (630 speakers of American English, with 974 tokens of syllabic /n/ and 9660 tokens of non-syllabic /n/). Lehiste (1964) is based on acoustic data from 5 speakers of Midwestern American English (sex unspecified). Sproat and Fujimura (1993) is based on data from 5 speakers, 2 of which were female. One male informant is described as a 'speaker of British English with a fair amount of American English influence' whilst all other subjects were speakers of Midwestern American English. Umeda (1976) is based on data from 1 male speaker of American English. Only Lehiste and I use a regular sentence frame format; data from other authors collapses different prosodic and sentence positions for target segments.

${ }^{15}$ Lehiste and Barry actually quote their formant values in Hz. I have converted their values into Bark using the formula $7 \ln \left(x / 650+\sqrt{ }\left(1+(x / 650)^{2}\right)\right)$ as used in the speech software PRAAT. The data quoted here from Barry specifically excludes prevocalic syllabic $/ 1 /$ in order to ease comparison with my own data.

${ }^{16}$ This table is given in $\mathrm{Hz}$ as Sproat and Fujimura only provide $\mathrm{F}_{2}-\mathrm{F}_{1}$ values in $\mathrm{Hz}$ : to do so in Bark would be meaningless as the Bark scale is a logarithmic scale. The formula 650 sinh (x / 7), as given in PRAAT, was used to convert Bark values into $\mathrm{Hz}$ values.
} 
The data in (16) and (17) concurs with descriptions given by Spencer (1995:214-6), Roach (1991:79) and Gimson (1989:202) who assert that syllabic /1/, like coda /1/ is always dark. However, before we adopt this claim wholesale we must consider the fact that, at least with respect to my own data, the dark quality of syllabic /1/ may be a construct of my experiment design ${ }^{17}$ : due to the nature of the carrier phrase, syllabic /l/ was always followed by a consonant ('How does _ translate?'), and never by a vowel. Barry (2000) provides some evidence that, at least in RP English, syllabic /1/ is regularly 'light' and onset-like in its quality when followed by a vowel initial word, rather than a pause or a consonant initial word. Here it is worth noting that syllabic /l/ in Lehiste's data was followed by a vowel initial word (her carrier phrase was 'Say the word _ instead'), and still syllabic /// remained 'dark'. This may turn out to be a dialectal difference between the two Englishes (as, for example, in the case of intervocalic /l/ which is clear in RP and dark in GenAm, according to Wells (1982:74)).

I believe that further investigation into the quality of a syllabic /1/ is worthwhile. Quality differences such as 'dark' and 'light' may provide valuable cues to the parsing of phonological strings. Such quality differences may demarcate prosodic boundaries and therefore these cues should have a place in the phonological representation. Given these assumptions it is vital to establish the quality of syllabic /1/ and whether or not this varies with context.

Let us now turn to the issue of duration and its place in phonological representation. Clark and Yallop (1995:67), Jones (1959:136) and Price (1980) have claimed that duration is a cue to syllabicity; syllabic consonants are purported to be longer than their non syllabic counterparts. This claim, however, is not immediately substantiated by the data presented in (18) and (19)

A comparison of $/ 1 /$ allophone durations ${ }^{18}$

\begin{tabular}{|l|l|l|l|l|}
\hline & Author & Syllabic & Onset & Coda \\
\hline \multirow{3}{*}{ Duration (ms) } & a. Toft & 86 & 81 & 116 \\
\cline { 2 - 5 } & b. Lehiste & 253 & - & - \\
\cline { 2 - 5 } & c. Barry & 81 & 95 & 78 \\
\cline { 2 - 5 } & d. Umeda & - & 66 & - \\
\hline
\end{tabular}

(19) A comparison of $/ \mathrm{n} /$ allophone durations ${ }^{19}$

\begin{tabular}{|l|l|l|l|l|}
\hline & Author & Syllabic & Onset & Coda \\
\hline Duration (ms) & a. Toft & 106 & 86 & 102 \\
\cline { 2 - 5 } & b. Umeda & - & 71 & (i) 81 (ii) 48 \\
\cline { 2 - 5 } & c. Byrd & 80 & 59 & 59 \\
\hline
\end{tabular}

First, it is clear that duration of onset vs. coda sonorants i.e. the non-syllabic sonorants is not identical, with the exception of the data from Byrd in (19c). The process of domain final lengthening of consonants is well established in the literature (e.g. Crystal and House 1987a,

\footnotetext{
${ }^{17}$ This was pointed out to me by Martin Barry (p.c.).

${ }^{18}$ This figure differs from the average duration quoted by Lehiste (actually $247 \mathrm{~ms}, \mathrm{p} .31$ ) in that it is calculated on the basis of the duration of syllabic /l/ when preceded by /p/, /t/ and /k/ only; Lehiste's average is based on syllabic /l/ preceded by 18 different obstruents but I have extracted the /p/, /t/ and / $/$ / values to assist comparison with my data.

${ }^{19}$ Two values for coda duration are quoted by Umeda. (i) = duration of coda $/ \mathrm{n} /$ when followed by a pause, whilst (ii) $=$ duration of coda $/ \mathrm{n} /$ when followed by a vowel initial word.
} 
Cutler et al 1997) and it may be that this can account for the longer coda durations in (18a), (19a) and (19bi). Whether syllabic consonants should be compared to their onset or coda counterparts is unclear. Given that syllabic consonants are inevitably domain final, perhaps codas do provide the best grounds for comparison. However, the results from (18a) and (19c) suggest that a direct comparison is not possible. Crystal and House (1987b) show that all consonants are lengthened under stress and it could be argued that this accounts for the data in (18a): my stimulus words for coda consonants were monosyllabic, whilst for syllabic consonants they were disyllabic and thus my coda consonants were elicited as part of stressed monosyllables while my syllabic consonants were not in stressed syllables (syllabic consonants are necessarily unstressed in English). In contrast, coda $/ \mathrm{n} / \mathrm{s}$ in Byrd (1993) are not restricted to monosyllabic stressed words (though no detail is provided as to how many tokens were indeed unstressed).

So far all that is clear is that the data does not yet support the strong claim that all syllabic consonants are necessarily cued by longer durations. It may be that claims concerning the longer duration of syllabic consonants vis a vis their non syllabic counterparts are based on a comparison of syllabic consonants vs. non syllabic consonants in a cluster, though this is nowhere stated explicitly. Thus the two /l/s in e.g. [b/kl] vs. [kli:n] should be compared with each other rather than the two /l/s in [b/kl] vs. [li:n]. The collection of such data for English awaits further research, however, it is perhaps interesting to consider some already available data from Icelandic.

Icelandic, much like English, has word final obstruent-sonorant sequences. However, whilst such word final sonorants are described as syllabic in English, they are not described as such in Icelandic (Ito 1987, Árnason 1980).

(20) Some word final obstruent sonorant sequences in English and Icelandic

\begin{tabular}{|l|l|}
\hline English & Icelandic \\
\hline /æpl/ apple & /apl/ strength \\
\hline /bætl/ battle & /fatl/ downfall \\
\hline /hækl/ hackle & /fykl/ bird \\
\hline /b $\Lambda$ tn/ button & /EItn/ one \\
\hline
\end{tabular}

If longer duration is a cue to syllabicity of consonants (Clark and Yallop, and Jones do not specifically restrict their claims to English) then the apparently non syllabic final sonorants of Icelandic should not be especially longer than their non syllabic word internal consonants. In other words, the /l/ in /apl/ 'strength' should be no longer than the /l/ in /plau:r/ 'blue', providing we can control for processes like phrase final lengthening. The following data is taken from Garnes (1976):

(21) Sonorant duration in Icelandic

\begin{tabular}{|l|l|l|}
\hline Position & /l/ & /n/ \\
\hline Singleton onset & {$[1]$ ög $98 \mathrm{~ms}$} & [n]einn $76 \mathrm{~ms}$ \\
\hline $\begin{array}{l}\text { Part of word internal cluster of } \\
\text { increasing sonority }\end{array}$ & ep[1]i $64 \mathrm{~ms}$ & vak[n]a $69 \mathrm{~ms}$ \\
\hline Word final, post obstruent & gut[1] $189 \mathrm{~ms}$ & vat[n] $260 \mathrm{~ms}$ \\
\hline
\end{tabular}

${ }^{20} \mathrm{pl-}$ and kn- are both possible word initial onsets in Icelandic. However Garnes does not provide data for words with such onsets. 
Whilst this data from Garnes must be treated with caution (her corpus contains no other words which either end in $/ \mathrm{tn} /$ or $/ \mathrm{tl} /$ or begin with a singleton $/ \mathrm{l} /$ or $/ \mathrm{n} /$ ), it would appear that word final post obstruent sonorants in Icelandic are considerably longer than their onset counterparts, either as singletons or as part of a cluster. One possible conclusion might be that Icelandic does in fact have syllabic consonants. Thus the claim that syllabicity is cued by duration could be maintained. Alternatively we could abandon the assumption that there is a direct relationship between longer duration and syllabicity. Clearly this is an area for further research.

For now, however, it is to an explanation of the behaviour observed and described in $\S 4$ and $\S 5$ that we turn. In the following section I outline a phonological framework where there are severe restrictions on the syllable template and strict conditions govern the occurrence of epenthetic schwas. Using this framework, in $\$ 7$ I then turn to an analysis of the data presented above.

\section{A phonological framework}

Government Phonology (GP) aims to provide a non-arbitrary account of phonological events by replacing the rule component of a phonology with a finite set of universal principles and parameters (contra Bromberger and Halle 1989). Paralleling Chomsky's 'principles and parameters' approach to the syntax of natural languages (Chomsky 1981, 1982, Culicover 1997), the different phonological systems of languages are captured through different combinations of parameter setting.

Like any school of thought Government Phonology also comes in a variety of flavours (for example, Harris 1994, Scheer 1998, Cyran 2000). With regard to constituency I shall primarily be following work by Kaye, Lowenstamm and Vergnaud (1990), Charette (1991a) and Harris (1994) whilst with regard to melody my work shall be based on Harris and Lindsey (1995).

\subsection{Prosodic structure}

The only constituents available in Government Phonology are the Onset, the Nucleus and the Rhyme, each of which may be maximally binary branching (Kaye, Lowenstamm and Vergnaud, henceforth KLV, 1990:198-199). No 'syllable' constituent is recognised (KLV 1990:200-201, Harris 1994: 45-46), but rather, domains are constructed of iterated OnsetNucleus pairs: neither a Nucleus, nor an Onset may form a domain on its own, nor may two Onsets (or two Nuclei) follow one another, without an intervening Nucleus (or Onset) (Harris 1994:160). No 'Coda' constituent is recognised either (Kaye 1990a): Any word final consonant is instead attached to an Onset, which is necessarily followed by a (licensed, empty) nucleus (see below).

Constituents are attached to the melody (i.e. segmental structure) via a timing unit, traditionally referred to as a skeletal point (Kaye 1989:125-139, Harris 1994:33-41). Thus phonological quantity, as manifested for example in the difference between light and heavy diphthongs, geminate and non-geminate consonants, and of course long and short vowels, is captured independently from both the prosodic and melodic tiers. To the best of my knowledge no work has been done within GP on establishing a relationship between the phonological and phonetic value(s) of skeletal points, in contrast to the now quite substantial 
literature available on the phonetic interpretation of the mora (e.g. Beckman 1982, Hubbard 1995, Barnes 2001). Thus one aim of this paper is to provide data for investigating this relationship between phonology and phonetics, specifically within a GP framework. Of course, whilst attempts at establishing a relationship between phonological structures and phonetic durations are, I believe, worthwhile, it remains clear that we must maintain a relational sense of time, and not an absolute one.

\subsection{Melody}

Language is primarily and auditory system of symbols. In so far as it is articulated it is also a motor system, but the motor aspect is clearly secondary to the auditory. In normal individuals the impulse to speech first takes effect in the sphere of auditory imagery and is then transmitted to the motor nerves that control the organs of speech. The motor processes and the accompanying motor feelings are not, however, the end, the final resting point. They are merely a means and a control leading to auditory perception in both speaker and hearer...Hence, the cycle of speech... begins and ends in the realm of sounds.

(Sapir 1921:18-18, quoted in Harris and Lindsey 2000:185)

Whilst the claim that linguistic units of sounds are decomposable into smaller units was adopted the best part of a century ago, the nature of these subparts remains a topic of discussion. In those approaches which adopt traditional features, such as $[+/-$ front $]$, $[+/-$ anterior] as the smallest phonological units, articulation is elevated to unwarranted levels of importance given the wealth of evidence showing that speech production is parasitic on speech perception ${ }^{21}$. The primacy of articulation is undermined not least by the fact (all too often dismissed) that the same acoustic signature can be achieved by very different articulatory means.

In contrast to many feature based approaches, Government Phonology takes seriously the relationship between phonological information and information in the speech signal. Sounds are composed of one or more monovalent elements, which although not in themselves acoustic events, are directly mappable onto gestalt patterns in the acoustic signal.

\footnotetext{
${ }^{21}$ Consider, for examples, studies showing how acquired deafness and distorted auditory feedback can impair speech production e.g. Perkell et al. 2000.
} 


\begin{tabular}{l||l} 
Symbol & Acoustic Pattern and notes \\
\hline $\mathrm{A}$ & $\begin{array}{l}\text { Central spectral energy mass (convergence of } \mathrm{F}_{1} \text { and } \mathrm{F}_{2} \text { ). Present in } \\
\text { uvulars and pharyngeals. } \\
\text { Low } \mathrm{F}_{1} \text { coupled with high spectral peak (convergence of } \mathrm{F}_{2} \text { and } \mathrm{F}_{3} \text { ). } \\
\text { Present in palatals and palatalized consonants. } \\
\text { Low spectral peak (convergence of } \mathrm{F}_{1} \text { and } \mathrm{F}_{2} \text { ). Present in labial vowels } \\
\text { and consonants. } \\
\text { Dispersed formant structure i.e. no salient spectral peak (a baseline on } \\
\text { which other resonances are superimposed). Present in velar consonants } \\
\text { Set of formant transitions associated with coronals }{ }^{22} \\
\mathrm{R}\end{array} \quad \begin{array}{l}\text { Aperiodic energy, the result of a narrowed stricture which produces } \\
\text { turbulent airflow. } \\
\text { Abrupt and sustained decrease in overall amplitude, independently } \\
\text { manifested as a glottal stop } \\
\text { Low frequency broad band murmur } \\
\text { High fundamental frequency, stiff vocal chords } \\
\text { Low fundamental frequency, slack vocal chords }\end{array}$ \\
$\mathrm{N}$ & $\begin{array}{l}\mathrm{H} \\
\mathrm{L}\end{array}$
\end{tabular}

Whilst this maximal element inventory is considerably smaller than any standard feature inventory (10 vs. 22 subsegmental units ${ }^{23}$ ), thereby substantially constraining the number of predicted combinations $(1023 \text { vs. } 4,194,304)^{24}$, work continues within the GP tradition to reduce the element set further (Jensen 1994, Ploch 1999) ${ }^{25}$. However, for the purposes of this paper I shall continue to use the 10 element set above, not least because any reduction in the set of elements risks also reducing the potential for directly mapping elements onto acousticauditory cues. I propose the following representations for the consonantal inventory of English:

\footnotetext{
${ }^{22}$ In fact, a single signature pattern for the element $\mathrm{R}$ has proved elusive, although see Kang's 1999 (non GP) work on the acoustic properties of coronals. An additional problem arises in proposing that coronality has an independent element on a par with others: the special properties of coronals (for example its propensity to assimilate) fail to be captured (Harris 1995:67-68).

${ }^{23}$ This total (22) is taken from Halle and Clements (1983).

${ }^{24}\left(2^{10}\right)-1=1023$ (empty set is excluded from total), $2^{22}=4,194,304$ (no empty set, with all features fully specified).

${ }^{25}$ This work reminds us to ask what is it that we are trying to capture with our feature/element sets. If we are trying to capture and characterise all and only phonemic contrasts, we may be aiming to reduce the set of features/elements such that only about 100-150 combinations can be generated, given that the largest known inventories contain approximately this number of segments e.g. !Xũ, with 141 segments (Crystal 1987;165). If this is our aim, a 10 element system results in considerable overgeneration. If, however, we wish to characterise all cues used in expressing these contrasts a larger set of combinations will be necessary. Quite how large a set of cues is necessary is a matter for empirical research: a universal set of acoustic-auditory cues is far from general acceptance (not least because of the historical bias towards articulation in phonetics and phonology). In reference to English Harris (1994) gives 10 cues, but more may be necessary to capture salient signal cues in other languages.
} 
(23) Internal representation of the consonantal inventory of Southern British English (broadly based on Harris 1994)

\begin{tabular}{|c|c|c|c|c|c|c|c|}
\hline $\begin{array}{l}\text { Bilabial } \\
\mathrm{p}\end{array}$ & $\begin{array}{l}\text { Labio- } \\
\text { dental }\end{array}$ & Dental & $\begin{array}{l}\text { Alveolar } \\
+\end{array}$ & Post-Alveolar & Palatal & $\begin{array}{l}\text { Velar } \\
k\end{array}$ & Glottal \\
\hline (@@.U.?.h.h.H) & & & (d@.R.R.h.h.H) & & & (g@.r.h.H) & \\
\hline \multirow[t]{4}{*}{ (@.U.?.h) } & & & (@.‥R.P.h) & & & (@..r.h) & \\
\hline & & & & $\mathrm{t} \int$ & & & \\
\hline & & & & (d $($ S.I.R.R.H) & & & \\
\hline & & & & (@.I.R.P) & & & \\
\hline \multirow{9}{*}{ m (@.U.r.N) } & & & $\mathrm{n}$ & & & $\eta$ & \\
\hline & & & (@.R.R.N) & & & (@.r.N) & \\
\hline & $\mathrm{f}$ & $\theta$ & $\mathrm{s}$ & $\int$ & & & h \\
\hline & (@@.U.h.H) & (f@.R.h.H) & (@@.R.h.H) & 6@@.I.R.h.H) & & & (@.h) \\
\hline & @.U.h) & (@.R.h) & (@.R.h. & (@.I.R.h. & & & \\
\hline & & & I & & $\mathrm{j}$ & w & \\
\hline & & & (@.R) & & (@.I) & (@.U) & \\
\hline & & & 1 & & & & \\
\hline & & & (@.R.?) & & & & \\
\hline
\end{tabular}

As can be seen from the table above, PEs often contain more than one element. However, there are certain restrictions on elemental combination (also known as fusion, and indicated by the symbol '.'). Universally each element may maximally occur once in any given expression. Each expression may also contain maximally one Head element: in principle any element may take the role either of Head (by convention the Head of a PE is underlined) or of Operator. Headedness represents the preponderance in the acoustic signal of the given element's signature over the signature of other elements ${ }^{26}$. The elemental composition of language specific sound inventories are established by examining the acoustic signal and matching the patterns observed with the patterns which represent different elements as described in (22) above. Thus, elemental composition is not stipulated but, at least in principle, established on independent grounds (Williams 1997).

The element@ @as special properties which warrant some discussion. It does not display the sort of active resonance properties that other resonance elements (A, I, U, R). Furthermore it is argued to be present in all expressions, although its auditory-acoustic signature is only manifested when @ is head of the given expression (Harris 1994:108-113). A PE that contains only @, as an operator, is known as an empty expression, and the nucleus to which such an expression is attached is known as an empty nucleus. Special principles govern the manifestation of such empty nuclei and these are discussed below.

\footnotetext{
${ }^{26}$ This is in fact an idealised scenario, as empirical support for this claim has so far proved elusive.
} 


\subsection{Empty nuclei}

Many languages exhibit vowel-zero alternations. The vowels involved in such alternations are typically reduced, for example the alternation $\dot{\mathrm{i}} \sim \varnothing$ in Moroccan Arabic (Kaye 1990b), and $\partial$ $\sim \varnothing$ in French (Charette 1991a). In Government Phonology, vowels which have this special property of alternating with zero are argued to be underlyingly empty (or in terms of the theory of elements outline above, to contain only operator @) and their interpretation is subject to the Empty Category Principle (ECP) and concomitant parameters:

(24) The Phonological Empty Category Principle

(Charette 1990:235, precise wording here taken from Kaye 1995:295)

A p-licensed (empty) category receives no phonetic interpretation

There are four potential circumstances under which an empty category, or specifically here, an empty nucleus, can be p-licensed.

(25) (Parametric) Conditions on p-licensing

(Kaye 1995:295, precise wording here my own)

A p-licensed (empty) category may receive no phonetic interpretation iff:

i. it is magically licensed

ii. it is within an Inter Onset governing domain

iii. it is domain final

iv. it is properly governed

Magic licensing (Kaye 1991) is concerned with nuclei preceding S+C clusters. As such it is not relevant to the discussion at hand and therefore no further consideration shall be given to it here. Inter Onset Government (Gussmann \& Cyran 1998, Lee 1999) is a governing relationship which may, in languages where this particular parameter is ON, be contracted between two onsets separated by a nucleus if certain substantive constraints are met (see $\S 6$ ). The domain final parameter, referred to in (i) above, is $\mathrm{ON}$ in those languages which allow apparent word final consonants (e.g. English) and OFF in those languages where words may only end in vowels (e.g. Cayuvava, Hawaiian). Given that GP holds that phonological strings consist of Onset-Nucleus pairs, those words, which appear to end in consonants, actually end in a nucleus. This nucleus is empty (it has no melodic content) and because it is silent it must be (by stipulation) p-licensed. By convention, a p-licensed category is indicated by underlining.

(26) Domain final p-licensing: representation of 'dog'

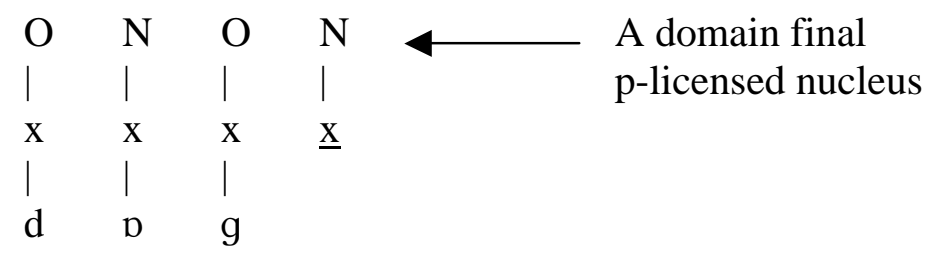

Finally, an empty category may remain without interpretation if the conditions for Proper Government are met. 
(27) Proper Government

(Kaye 1995:295, precise wording here taken from Charette 1998:170)

A nucleus $\alpha$ properly governs and empty nucleus $\beta$ iff:

i. $\alpha$ and $\beta$ are adjacent on the nuclear projection

ii. $\alpha$ is not itself p-licensed

iii. $\alpha$ is not a government licensor (for its onset).

(28) Government Licensing (Charette 1990:242)

For a governing relation to hold between a non-nuclear head A and its complement B, A must be licensed to govern by its nucleus.

The clause in (27iii) refers to situations where a consonant cluster intervenes between the two nuclei. Let us first examine the simpler case of Proper Government when the empty nucleus is preceded by a singleton. An underlyingly empty nucleus is realised as zero when it is properly governed by a following unlicensed nucleus. If Proper Government fails to apply the empty nucleus is phonetically interpreted.

(29) Bulgarian singular plural alternation (data taken from Cowan and Rakusan 1985)

$$
\begin{aligned}
& \begin{array}{l}
\text { bobər } \sim \text { bobri 'beaver' } \\
\text { kosəm } \sim \text { kosmi } \\
\text { 'hair' }
\end{array} \\
& \text { Proper Government fails. } \\
& \mathrm{N}^{2} \text { and } \mathrm{N}^{3} \text { are adjacent on the } \\
& \text { nuclear projection, but } \mathrm{N}^{3} \text { is } \\
& \text { itself p-licensed. Consequently }
\end{aligned}
$$

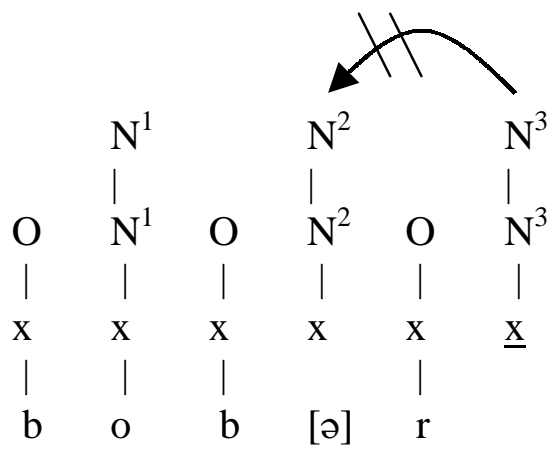

$$
\begin{array}{ll}
\text { lavər } \sim \text { lavri } & \text { 'laurel' } \\
\text { teatər } \sim \text { teatri } & \text { 'theatre' }
\end{array}
$$

Proper Government succeeds. $\mathrm{N}^{2}$ and $\mathrm{N}^{3}$ adjacent on the nuclear projection, $\mathrm{N}^{3}$ is not itself $\mathrm{p}$-licensed (we know this because it has melodic content), and $\mathrm{N}^{3}$ is not preceded by a

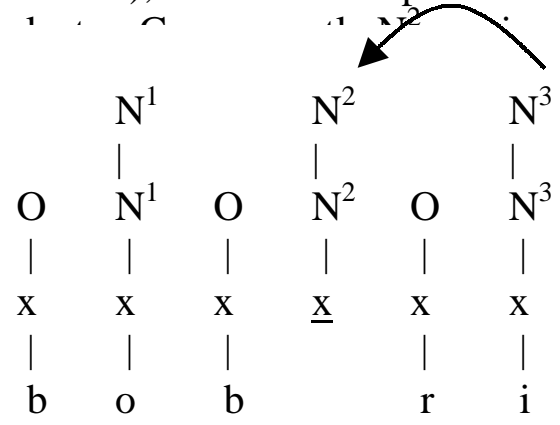

Now let us consider the more complex case where a consonant cluster does intervene between the two nuclei. 
(30) Failure of p-licensing when consonant cluster intervenes. Fr. 'secret'

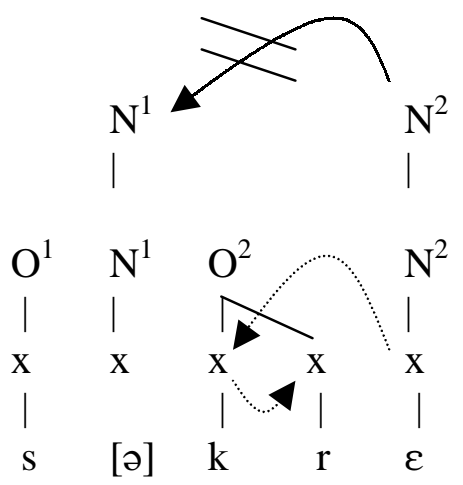

\author{
Proper Government fails \\ $\mathrm{N}^{1}$ and $\mathrm{N}^{2}$ are adjacent on the relevant \\ projection \\ but an consonant cluster intervenes \\ $\mathrm{O}^{2}$ requires a license to govern its complement \\ and this it gains $\mathrm{N}^{2}$ from, leaving $\mathrm{N}^{2}$ unable \\ to Properly Govern $\mathrm{N}^{1}$
}

Finally we note a third situation: that when a empty nucleus which could be properly governed and thereby p-licensed, is preceded by a consonant cluster. In such instances, Proper Government and Government Licensing interact, though the nature of their interaction is parametrically set.

(31) Parametric interaction of Government Licensing and Proper Government

French: (word internally) only non p-licensed empty nuclei may act as Government Licensors

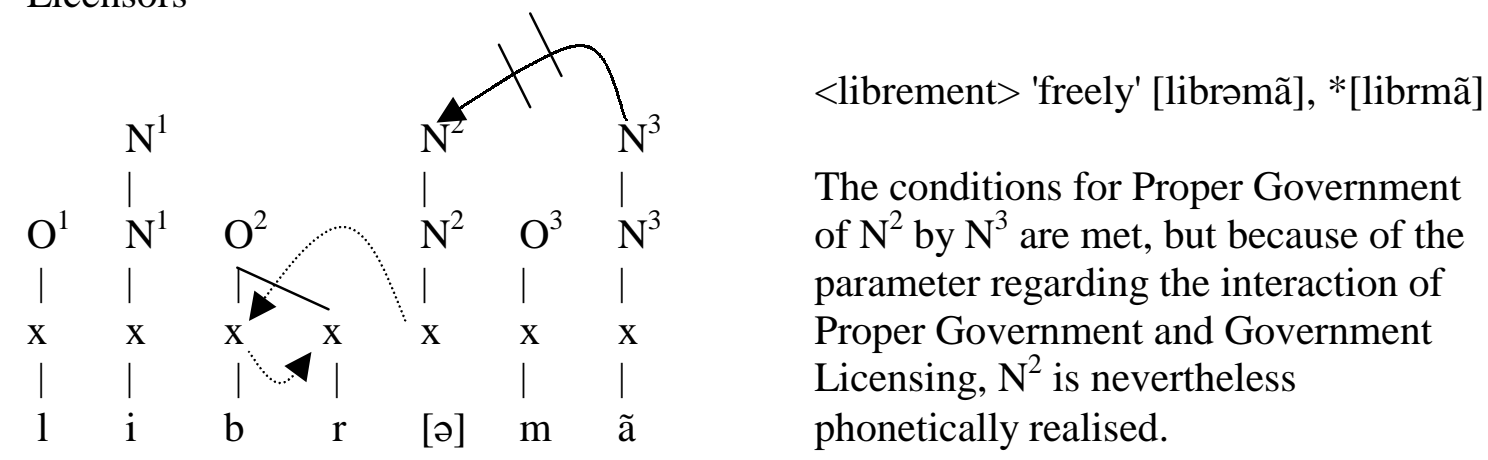

Polish: (word internally) p-licensed empty nuclei may act as Government Licensors

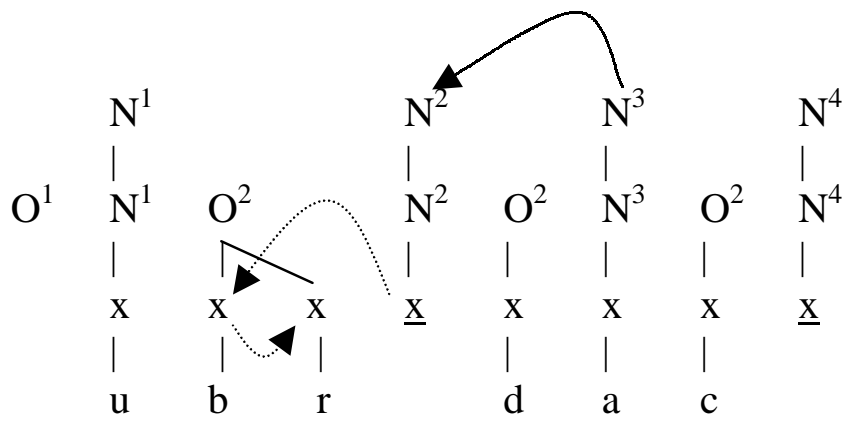
<ubrdac>, 'imagine'
[ubrdac], *[ubrədac]
The conditions for Proper Government of $\mathrm{N}^{2}$ are met, and $\mathrm{N}^{2}$ may indeed remain silent because of the different parameter setting in Polish vis a vis French.

What is interesting about the examples in (31) is the interaction of two principles of Government Phonology (for more details see Charette 1991b). We have spent some time on this interaction as we shall see a similar case of interaction, though between two different principles, when we come to the phonological analysis in $\S 6$ and $\$ 7$. 
Overall it may be said that the key issue to have taken from this section is that there are strict principles governing the (non) interpretation of empty nuclei. Unless certain conditions are met empty nuclei are phonetically interpreted as reduced vowels, typically as schwa.

\section{$7 \quad$ Towards a phonological analysis}

As we saw above, 'syllables' in GP are made up of Onset-Nucleus pairs. Thus the syllabification of a world like 'button' necessarily includes a nuclear constituent between the $/ \mathrm{t} /$ and the $/ \mathrm{n} /{ }^{27}$. Furthermore, we have seen that GP has strict principles governing the non interpretation of nuclei; only p-licensed empty nuclei can remain without phonetic interpretation. Given this let us consider the predictions we can make concerning the realization of a word like 'button'

(32) Phonological structure for 'button'

\begin{tabular}{|c|c|c|c|c|}
\hline$O$ & $\mathrm{~N}^{1}$ & $\mathrm{O}$ & $\mathrm{N}^{2}$ & $\mathrm{O}$ \\
\hline | & | & | & | & | \\
\hline $\begin{array}{l}x \\
\text { a }\end{array}$ & x & $\begin{array}{l}x \\
\mid\end{array}$ & $\mathrm{X}$ & $\mathrm{X}$ \\
\hline$b$ & $\Lambda$ & $\mathrm{t}$ & ? & $\mathrm{n}$ \\
\hline
\end{tabular}

What can we predict about the (non) interpretation of $\mathrm{N}^{2}$ ? Are any of the conditions on $\mathrm{p}$ licensing met? If they are, we predict $\mathrm{N}^{2}$ to be silent. If none of the conditions on p-licensing are met we predict $\mathrm{N}^{2}$ to be phonetically interpreted.

$\mathrm{N}^{2}$ is not domain final, so it is not p-licensed through parametrically set domain final p-licensing. $\mathrm{N}^{2}$ cannot be Properly Governed: it is followed by a empty nucleus which is itself p-licensed i.e. $\mathrm{N}^{3}$. $\mathrm{N}^{2}$ cannot be Magically Licensed (we are not dealing with an $\mathrm{S}+\mathrm{C}$ cluster). Our only hope for meeting one of the conditions on p-licensing now lies with Inter Onset Government.

\section{(33) Inter Onset Government}

An Inter Onset Governing relationship may be contracted between an onset $\alpha$ and onset $\beta$ iff:

i) $\alpha$ and $\beta$ are adjacent at the Onset Projection

ii) $\alpha$ is a good Inter Onset governor and $\beta$ a good Inter Onset governee, in terms of substantive constraints.

Note 1: An Inter Onset governing relation may be head final (e.g. Korean, Heo 1994) or head initial (e.g. Polish, Gussmann \& Cyran 1998). The direction of Inter Onset Government is parametrically set.

Note 2: The substantive constraints on Inter Onset Government are similar to those for Constituent Government ${ }^{28}$

\footnotetext{
${ }^{27}$ Of course we are assuming that $/ \mathrm{tn}$ / cannot form a branching onset on the grounds, for example, that no English word could begin /tn/. For a principled GP explanation of why this is not possible see KLV 1985.

${ }^{28}$ The precise nature of substantive constraints for Inter Onset Government is not yet entirely clear. They may turn out to be linked to the direction of Inter Onset Government, head-final I-O government implicating Transconstituent-like substantive constraints, and head initial I-O government implicating Constituent-like substantive constraints (Toft 1999) but this is a subject for further research. For the purposes of this paper we
} 
The substantive constraints on Constituent Government stipulate that the Governor be headed and more complex than the Governee, and that the Governor and Governee share at most one element other than the element @ (Kaye, Lowenstamm \& Vergnaud 1990, Harris 1990). Given these constraints it is not possible for the $/ \mathrm{t} /$ and the $/ \mathrm{n} /$ in 'button' to enter into an Inter Onset governing relationship: the elemental representation of $/ \mathrm{t} /$ is $(@ \text {.h.?. } \underline{\mathrm{R}} \text {. H })^{29}$, whilst for $/ \mathrm{n} /$ it is (@.R.R.N). The two expressions have (@), (R) and (?) in common i.e. too many elements in common, and thus an Inter Onset Governing relationship is not entered into. For similar reasons Inter Onset Government is ruled out between the stop and the liquid in a word like 'bottle'.

Here it is also worth noting that the acoustic result of Inter Onset Government (IOG) sounds very much like a branching onset30, and not like one consonant followed by a syllabic consonant. For example, one case in English where it has been suggested that Inter Onset Government may be at work is in the word 'chocolate', which is typically pronounce [t $\int \mathrm{pkl} \mathrm{t}$ ] but may be pronounced [t $\int$ pkolət] (Wells 2000:137). It is proposed that IOG is active when the former pronunciation is chosen, and inactive when the latter is opted for, thus resulting in an epenthetic schwa. What is interesting for us is that the $[\mathrm{kl}]$ sequence possibly arising from IOG does not sound at all like the $/ \mathrm{kl} /$ sequence where $/ \mathrm{l} /$ is syllabic, as in word like 'buckle'.

We have now seen that none of the conditions are met for the p-licensing of $\mathrm{N} 2$ in (32): it is not domain final, it is not properly governed, it is not magically licensed, nor is it subject to Inter Onset Government. From this we can conclude that N2 must be phonetically realised, and our next question arises: How is this N2 phonetically realised? The results reported in $\$ 4$ show that words containing a potential syllabic /1/ never contained a schwa, whilst words containing a potential syllabic $/ \mathrm{n} /$ either contained no schwa, when the $/ \mathrm{n} /$ was preceded by a coronal, or such words contained a schwa-/n/ sequence, when the preceding syllable ended in a non coronal.

To explain this behaviour I propose the following structures for syllabic /1/ and syllabic $/ \mathrm{n} /$ :

(34) Structures for syllabic /l/ and syllabic /n/

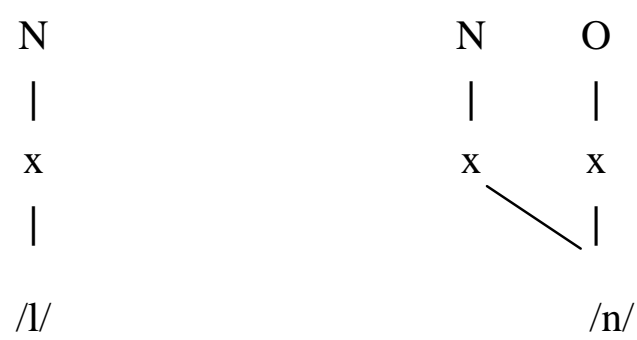

Syllabic /l/, unlike non syllabic /1/ is attached directly to a nuclear constituent, whilst syllabic $/ \mathrm{n} /$ is attached to both a onset constituent, and the preceding nuclear constituent, as a result of spreading. Within Government Phonology literature, such a nucleus, which shares its content with a following onset is known as a pseudo-empty nucleus (Hawarth 1994, Charette 1998)

shall maintain the common assumption that (head initial) Inter Onset Government is subject to Constituent-like substantive constraints.

${ }^{29}$ When the /t/ is not normally released, as is often the case with stops preceding syllabic consonants, its elemental representation is (@.?. R. H)

${ }^{30}$ Or rhyme onset sequence, where IOG is head final. 
This spreading takes place when the $/ \mathrm{n} /$ is Head Licensed by the preceding consonant. Head Licensing is established when two onsets, adjacent at the relevant projection, contain the same element as head. This gives syllabic structures for words like 'button' and 'bottle' as in (35 $a, b)$ :

$$
\text { Syllabic representation of 'button' [bᄉtn] }
$$

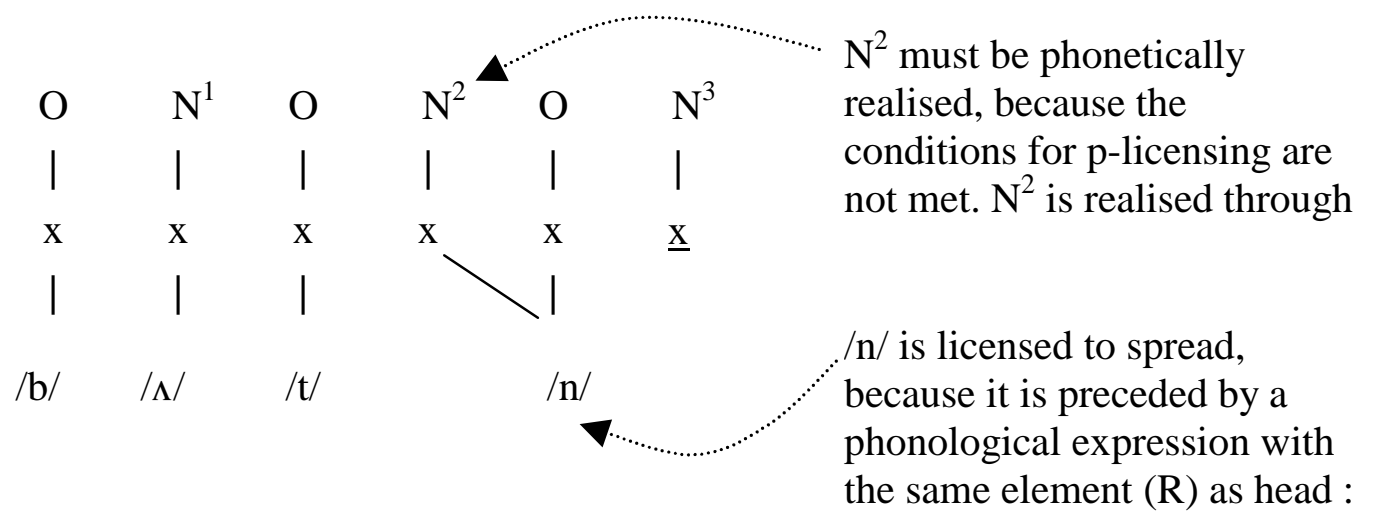

(35b) Syllabic representation of 'bottle' [bptl]

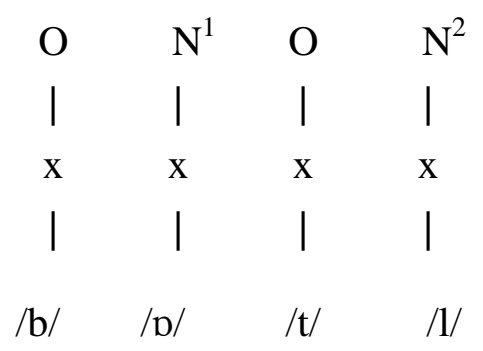

On what grounds do I make these proposals? First it is clear from minimal pairs such as 'gambolling' [gæmblın] vs. 'gambling' [gæmblın], 'finally' [faınli] vs. 'finely' [fainli], 'evening' (<vb. meaning 'to smooth') [i:vnın] vs. 'evening' (time of day) [i:vnı]], that syllabic /l/ and syllabic $/ \mathrm{n} /$ are not the same as their non syllabic counterparts. This rules out representations whereby syllabic /1/ and syllabic /n/ are directly and uniquely attached to an onset constituent, as is the representation of non-syllabic $/ 1 /$ and $/ \mathrm{n} /$.

The experimental results in $\S 4$ showed that for potential syllabic $/ \mathrm{n} /$ there is some free variation between [n] and [ən], irrespective of context. For example, following $/ t /$, [n] occurred $85 \%$ of the time, whilst [ən] occurred $15 \%$ of the time. Additionally, the suffix '-en', one possible source for syllabic $/ \mathrm{n} /$, surfaces either as $[\mathrm{n}]$, as in [redn], or as [ən], as in [swəulən], depending on the (coronal) place of the consonant preceding the suffix. The possibility for this variation to exist must somehow be captured in whatever representation is proposed for syllabic /n/.

This variation can indeed be captured by proposing the structure for syllabic $/ \mathrm{n} / \mathrm{as}$ given in (34), and in addition, a condition on the spreading of $/ \mathrm{n} /:$ : $/ \mathrm{n}$ may only spread into the preceding nucleus when head licensed to do so by an onset adjacent at the relevant projection with the same element as head. When the onset preceding $/ \mathrm{n} /$ is not capable of head licensing 
the $/ \mathrm{n} /$, no spreading takes place. In such circumstances, the intervening nucleus must still be realised, but in these cases it is realised as a default vowel, or in other words, as a schwa.

Syllabic representation of 'bacon'

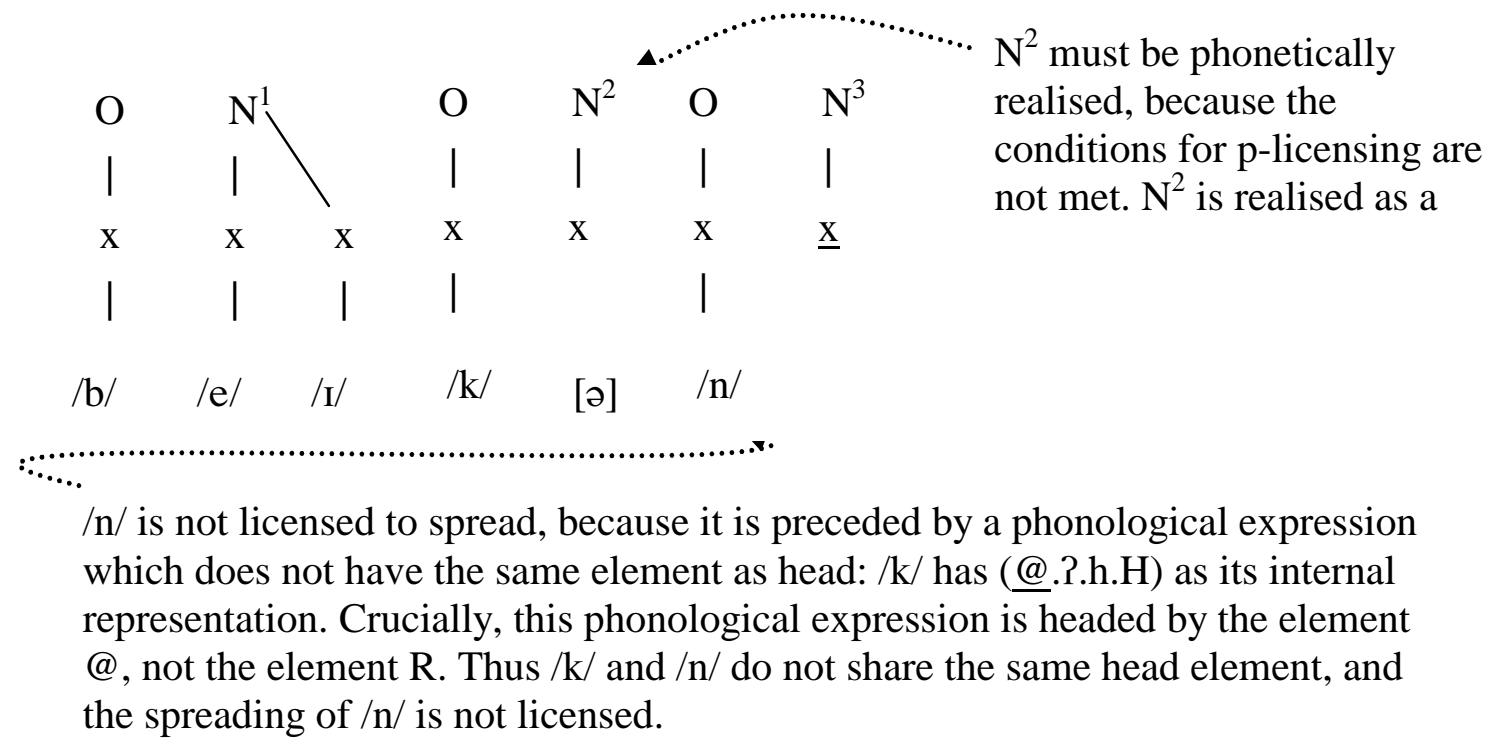

As for why syllabic $/ \mathrm{n} /$ is never found following a nasal-stop cluster, even when that nasalstop cluster is coronal, there are two possible explanations: (1) some sort of OCP effect prevents the spreading of $/ \mathrm{n} /$ or (2) when a potential syllabic $/ \mathrm{n} /$ is preceded by a cluster, Head Licensing comes into conflict with Government Licensing (in much the same way as we saw Government Licensing coming into conflict with Proper Government in §5.3). In this conflict Government Licensing wins out as, I shall claim, a License to Govern cannot be given by a nucleus with content shared with other constituents. Briefly I consider each of these proposals in turn below.

In the experiment described in $\S 4 \mathrm{I}$ investigated only nasal-stop clusters preceding potential syllabic consonants. Without evidence as to the behaviour of potential syllabics following other types of clusters e.g. /st/ clusters as in 'crystal' or 'Houston', it is not possible to rule out some sort of OCP influence of the $/ \mathrm{n} /$ in the cluster on the potential syllabic $/ \mathrm{n} /$, forcing a schwa to occur between the two $/ \mathrm{n} / \mathrm{s}$ to separate them. I remain sceptical of this proposal as the two $/ \mathrm{n} / \mathrm{s}$ are not adjacent at any level, given the intervening stop consonant and therefore interaction would be unlikely, but until further experimental evidence is gathered the possibility of an OCP effects has to be entertained.

As an explanation for the non occurrence of syllabic /n/ following a /nt/ cluster I would rather adopt an approach under which two licensing principles (Head Licensing and Government Licensing) come into conflict, the higher ranked of the two (Government Licensing) winning out. Government Licensing is concerned with the ability of a onset head to license its complement. In order for that head to license its onset, it must receive licence to do so. As we saw in $\$ 6.3$ languages vary as to what may provide the licence to govern to a onset head (Charette 1990, 1991a). In some languages a p-licensed nucleus may act as a Government licensor (e.g. Polish), whilst in others only a realised nucleus, i.e. one with phonetic content, may act as a Government licensor (e.g. French). Thus occasions can arise when Proper Government and Government Licensing come into conflict and the solution depends on the language specific ranking of these two principles. I wish to extend these ideas in two ways (1) to propose that Head Licensing and Government Licensing can also come 
into conflict in those languages where both principles are active, and (2) to propose that a licence to govern can be given by either a nucleus which shares its content with an adjacent onset, i.e. a pseudo-empty nucleus, or by a nucleus which does not share any content with an adjacent onset. In the latter case, the nucleus may contain either melodic content or be a genuinely empty (as opposed to a pseudo-empty) nucleus. A parameter setting decides which option is chosen. In English, the parameter is set such that a nucleus which provides a license to govern must not be a pseudo-empty nucleus.

(37) The interaction of Head Licensing with Government Licensing: the failure of a syllabic $/ \mathrm{n} /$ to be realised after an $/ \mathrm{nt} /$ cluster.

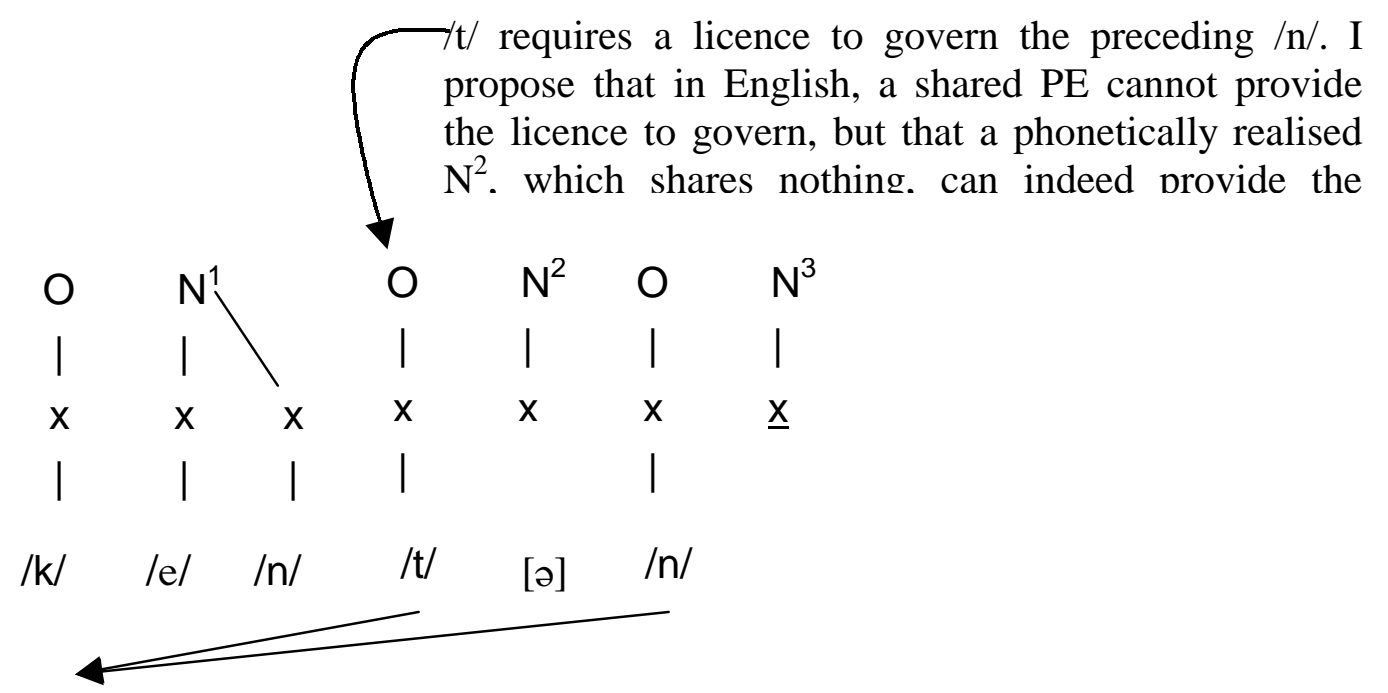

$/ \mathrm{t} /$ and $/ \mathrm{n} /$ both have the element $(\mathrm{R})$ as their head, and thus the conditions for Head Licensing are met. However /n/ does not spread, because the principle of Government Licensing, along with the language specific parameter that precludes a shared PE from providing the licence to govern, outranks the

As for syllabic /1/, we saw in $\S 4$ that it is found after clusters as well as singletons. This is not surprising if we accept the proposals that syllabic $/ 1 /$ is attached directly and uniquely to a nucleus. The PE representing syllabic $/ 1 /$ is not shared, and thus when it comes to Government Licensing the head of the preceding cluster, no conflict arises, and syllabic /1/ may indeed follow the given cluster, unlike syllabic $/ \mathrm{n} /$

Reconsidering now to the representation of syllabic /l/, I propose that this segment be directly attached to a nuclear constituent. Theory internally to Government Phonology there are no restriction on the set of elements which may attach to either a nuclear or non-nuclear constituent (cf. the one mouth principle, Anderson and Ewen 1987, Clements 1991). Theory externally, however, we must, as an upshot of my proposal, ask ourselves whether it is legitimate to treat syllabic /1/ as a vowel.

Let us consider definitions which have been made concerning what is and what is not a vowel or a consonant. A vowel can be defined articulatorily as involving no major stricture in the vocal tract (Ladefoged and Maddieson 1996:281), or acoustically as having relatively a long interval of periodic energy with three clear formants (Johnson 1997). Phonologically speaking, a structural definition is usually given for vowels: that which is found at the centre of a syllable, or acts as a syllable on its own. On each of these grounds it could be argued that 
syllabic /1/ is indeed very vowel-like. Phonetically speaking, /// is the most sonorous of oral consonants, having vowel-like formant characteristics, and can indeed be produced without any occlusion (Ladefoged and Maddieson 1996). Syllabic /1/ is also vowel-like phonologically speaking: it may occur after any onset (recall that syllabic $/ \mathrm{n} /$ does not show this behaviour), and can indeed form a syllable on its own, as in 'bottle'. Thus there seem to be no strong grounds for ruling out my proposal that syllabic /1/ is indeed attached directly to a nuclear constituent. Such an analysis would explain why no variation is seen in the realisation of potential syllabic /1/ (there is no 'space' in the syllabic structure, contrary to the case of syllabic $/ \mathrm{n} /$ ).

According to my proposals syllabic /l/ is attached to one timing slot whilst syllabic $/ \mathrm{n} /$ is attached to two timing slots. In some sense, then, I would appear to be claiming that syllabic /n/ is longer than syllabic /l/. The data presented in (11) and (14) do appear to support the claim that syllabic / $/$ / and syllabic /n/ have different durational structures although it is clear that my data does not support any claim that syllabic $/ \mathrm{n} /$ is twice as long as syllabic $/ 1 /$; in my data syllabic $/ \mathrm{n} /$ is approximately $20 \%$ longer than syllabic /1/ (this difference cannot be due to any inherent differences between $/ 1 /$ and $/ \mathrm{n} /$, e.g. because of the different articulators involved, on the grounds that the difference between onset $/ 1 /$ and onset $/ \mathrm{n} /$ is only approximately 6\%). This prompts the questions as to how skeletal slots should be phonetically interpreted. An in-depth exploration of this issue is, unfortunately, beyond the scope of the current paper but I shall briefly identify some of the issues that should be borne in mind.

No author, to the best of my knowledge, claims that all timing slots are equal. First of all there are the well known facts concerning onsets and their non-role in syllable weight calculation. GP researchers would not refute these facts, yet they maintain that skeletal positions are in fact attached to onsets. Thus, at some levels, such researchers must recognised that the skeletal slot attached to the [k] of [kat] is not the same as the skeletal slot attached to the [a] or [t] of that same expression. Some researchers working within Moraic Phonology (e.g. Hubbard 1995) also recognise that not all moras are equal, making a distinction between syllabic/head moras (those attached to nuclei) and non-syllabic/weak moras (those attached to the rhyme/onset). Another issue that needs to be considered is the perception of duration. Whilst the difference between syllabic /1/ and coda /l/ or syllabic /n/ and onset /n/ may be statistically significant in the raw time dimension, it is not clear that such differences are perceptually significant. Finally, it may be the case that intrinsic segmental phonetic length is not cognitively represented at all, but is merely a by-product of either the acoustics or the articulation (cf. Fowler 1977), depending upon one's beliefs about the relative importance of these two spheres in phonology. 


\section{Conclusions}

In this paper I have presented the results of an acoustic investigation into the nature of syllabic /1/ and syllabic /n/ in Southern British English. These showed that syllabic /1/ and syllabic $/ \mathrm{n} /$ behave quite differently from each other, in at least three ways. The distribution of syllabic $/ \mathrm{n} /$, but not syllabic $/ 1 /$, is sensitive to the place of articulation of the immediately preceding singleton consonant. A potentially syllabic $/ \mathrm{n} /$ is only actually realised as syllabic when preceded by a homorganic, i.e. coronal consonant. When $/ \mathrm{n} /$ is preceded by a non coronal consonant, the potential syllabic consonant is actually realised as /ən/. Syllabic /1/, on the other hand has no such restrictions on its distribution, for a potential syllabic $/ 1 /$ is realised as a syllabic /l/ (distinct from a schwa-/l/ sequence) irrespective of the place of the preceding consonant.

Secondly, the distribution of syllabic $/ \mathrm{n} /$ is also affected by the structural complexity of its context, i.e. whether or not it is preceded by a singleton or a cluster: if a potential syllabic $/ \mathrm{n} /$ is preceded by a nasal-stop cluster, the potential syllabic $/ \mathrm{n} /$ is always realised as /ən/, even when preceded by a homorganic cluster. Once again, syllabic /l/ behaves in a different way: a potentially syllabic /l/ is always realised as an actual syllabic /1/ irrespective of the place of the preceding nasal-stop cluster. Thirdly, with respect to duration syllabic $/ \mathrm{n} /$ is akin to coda $/ \mathrm{n} /$, both being significantly longer than onset $/ \mathrm{n} /$. Syllabic $/ \mathrm{l} /$, however, is not akin to coda $/ 1 /$ in duration, but is rather significantly shorter than coda $/ 1 /$, and approximately the same duration as onset $/ \mathrm{l} /$.

In the second half of this paper I proposed that these differences in behaviour can best be explained by proposing differences in their syllabic structure. This is a new proposal, quite unlike those made by previous researchers. Chomsky and Halle, for example, proposed that syllabic /l/ and syllabic /n/ should have fundamentally the same feature bundles:

(38) Feature tables from Chomsky and Halle 1968:354

\section{VOWELS \\ SYLLABIC LIQUIDS \\ SYLLABIC NASALS \\ NON SYLLABIC LIQUIDS \\ NON SYLLABIC NASALS \\ GLIDES \\ OBSTRUENTS}

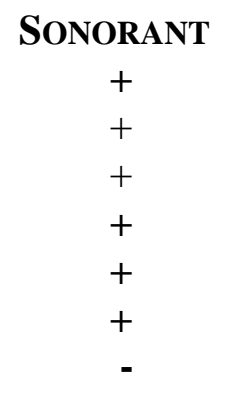

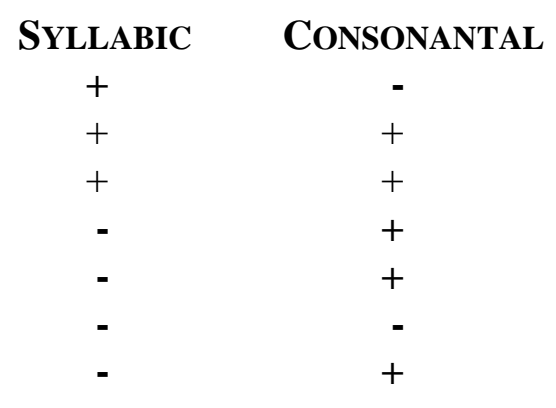

Wells (1995), Gimson (1989) and Gussmann (1991) have also proposed that syllabic /1/ and syllabic /n/ be treated uniformly, both being underlying composed of a schwa+consonant sequence.

I, on the other hand, propose that syllabic /n/ and syllabic /1/ be represented differently, on account of their different behaviours. If syllabic $/ \mathrm{n} /$ and syllabic $/ \mathrm{l} /$ are represented differently it is not surprising that they also behave different. The representations I proposed in (34) are here repeated as (39) for convenience: 
(39) Structures for syllabic /l/ and syllabic /n/

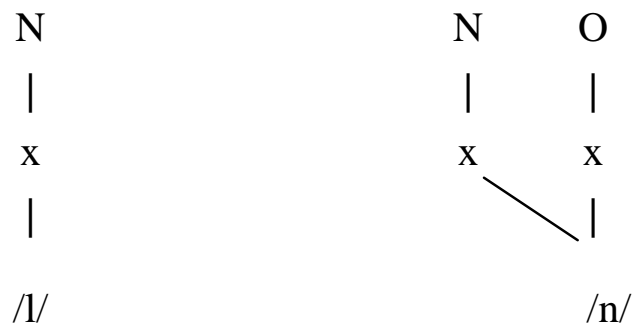

By proposing that syllabic $/ \mathrm{l} /$ is attached directly to a nuclear constituent I capture that fact that potential syllabic /l/ is always realised as syllabic /l/ regardless of the nature of the preceding onset. As discussed in $\$ 7$ above, there are no theoretical or definitional grounds for ruling out the interpretation of syllabic $/ \mathrm{l} /$ as a vowel. By proposing that syllabic $/ \mathrm{n} / \mathrm{is}$ attached to a onset, and that this $/ \mathrm{n} /$ may spread when the conditions for head licensing are met, I capture and explain the variability of potential syllabic $/ \mathrm{n} /$, which is sometimes realised as [n] and sometimes as [ən], when preceded by a singleton. Finally I explain the non occurrence of syllabic /n/ after clusters by proposing that phonological expressions which are shared between two constituents are not able to provide a license to govern to the head of the preceding cluster.

Questions which still remain to be investigated acoustically, and which may provide further answers to help with a phonological analysis include the role of voicing and manner in the distribution of syllabic consonants. Preliminary results from the pilot study of one speaker with an expanded set of singleton contexts suggest that voicing does not effect the distribution of syllabic $/ \mathrm{n} /\left(\chi^{2}(1)=0.12, \mathrm{p}=0.73\right)$, but does effect the distribution of syllabic $/ 1 /\left(\chi^{2}(1)=\right.$ $5.50, \mathrm{p}=0.019)$. In addition these results suggest that the distribution of syllabic $/ 1 /$ is not affected by the manner of the preceding singleton $\left(\chi^{2}(1)=0.017, p=0.896\right)^{31}$. With regard to $/ \mathrm{n} /$, whilst statistically speaking there is no significant effect of manner on the occurrence of syllabic $/ \mathrm{n} /\left(\chi^{2}(1)=3.520, \mathrm{p}=0.061\right)$, both visual inspection and the proximity of the $\mathrm{p}$ value to the arbitrarily set level of significance suggest that manner may play some role in distribution of syllabic $/ \mathrm{n} /$, with more occurrences of syllabic $/ \mathrm{n} /$ following fricatives rather than stops. These may provide fruitful ground for future research.

\footnotetext{
${ }^{31}$ This chi-squared was obtained from a table where $50 \%$ of the cells have an expected count less than 5 . As a consequence the value obtained for $\mathrm{p}$ may be inaccurately low.
} 
(40) Role of voicing in distribution of syllabic / $/$ / and syllabic /n/ (subject 1 )

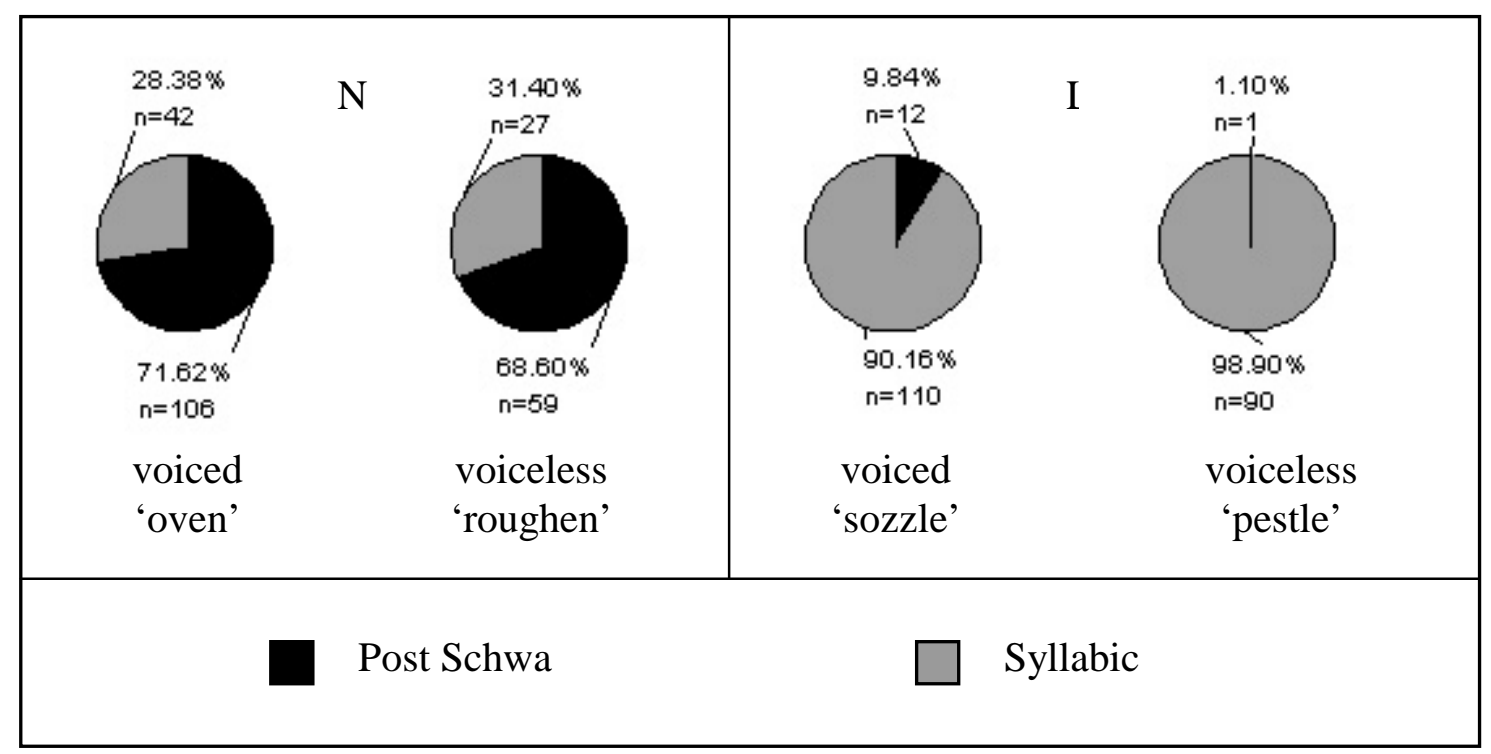

(41) Role of manner in distribution of syllabic /1/ and syllabic /n/ (subject 1)

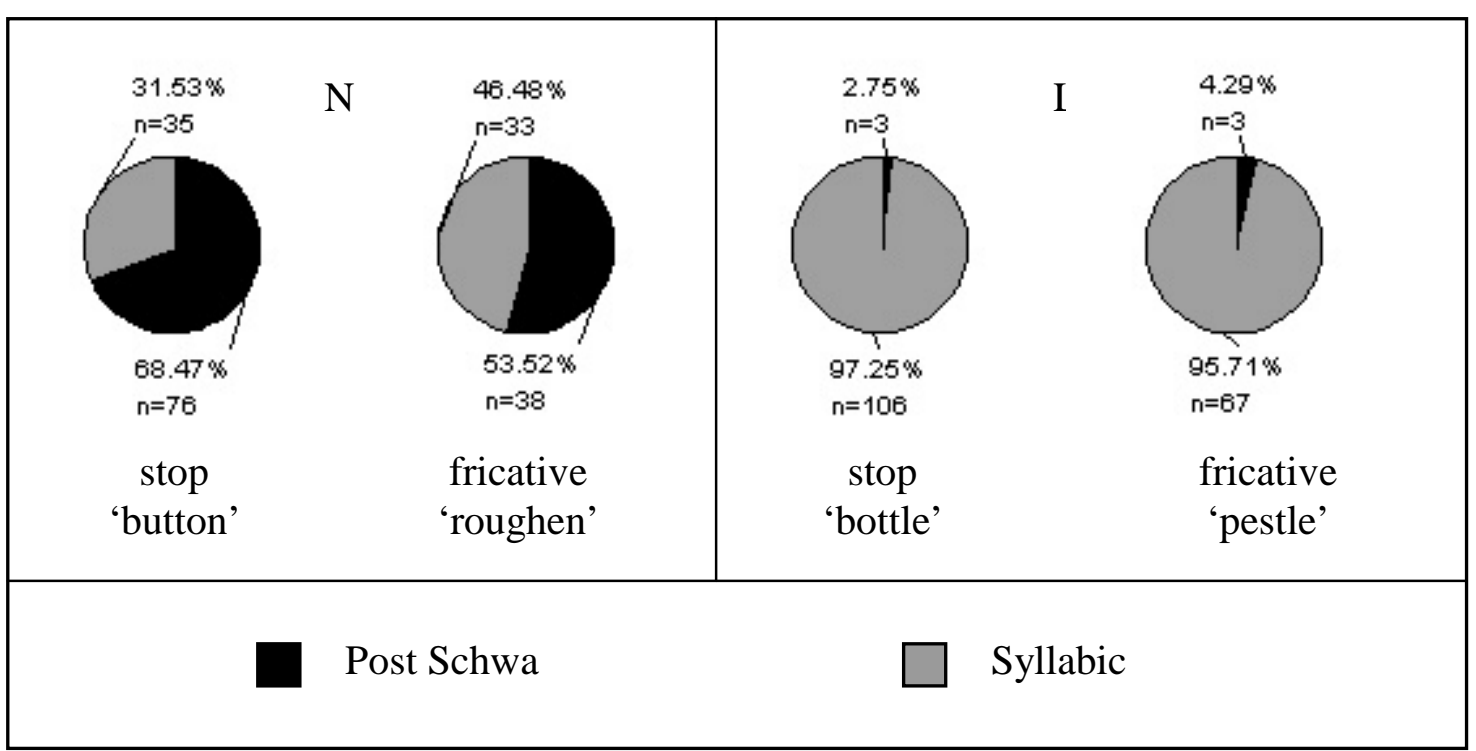

In conclusion I have shown that syllabic /l/ and syllabic /n/ behave in ways which do not justify a uniform analysis. Instead I have proposed distinct syllabic structures and new interactions of well established principles in Government Phonology, providing an analysis which I believe can elegantly capture different behaviours of syllabic /1/ and syllabic $/ \mathrm{n} / \mathrm{in}$ Southern British English. I have pointed out some areas for further research into the same topic and would hope to stimulate investigation into syllabic consonants in other dialects and languages. For example, it would be interesting to investigate syllabics in tapping dialects of English, where syllabic /1/ and syllabic /n/ have different effects on the preceding consonant: 
when not part of a cluster, /t/ is flapped before syllabic [1], but not before syllabic [n] e.g. Am. Eng. [bıtn] but [ba:tl] (Wells 2000). I also hope that this paper has shown how phonological insight can be informed by phonetic research.

\section{Acknowledgements}

This research was funded by the Students Award Agency for Scotland, Grant No. 10484396. I am very grateful to my informants, audiences at the 9th Manchester Phonology Meeting, ConSOLE X, Monik Charette, Bernard Howard, Wouter Jansen, Jahan Latif and Justin Watkins.

\section{References}

Anderson, J. \& Ewen, C. (1987) Principles of Dependency Phonology. Cambridge: Cambridge University Press.

Árnason, K. (1980) Quantity in historical phonology: Icelandic and related cases. Cambridge: Cambridge University Press.

Barnes, J. (2001) Syllable-weight isochrony and speech timing in Turkish. Talk given at the Conference on the Phonetics-Phonology Interface, ZAS, Berlin.

Barry, M. (2000) A phonetic and phonological investigation of English clear and dark syllabic /1/. Bulletin de la Communication Parlée No. 5 (Les Cahiers de l'I.C.P). pp 77-87.

Beckman, M. (1982) Segment duration and the 'Mora' in Japanese. Phonetica 39:113-135.

Bell, A. (1978) Syllabic consonants. In Greenberg, J. (Ed.) Universals of Human language. Volume 2: Phonology. Stanford: Stanford University Press. pp 153-201.

Blevins, J. (1995) The syllable in phonological theory. In J. Goldsmith (ed.) The handbook of phonological theory. Oxford: Blackwell.

Bloomfield, L. (1933) Language. London: George Allen \& Unwin Ltd.

Bromberger, S. \& Halle, M. (1989) Why Phonology is Different. Linguistic Inquiry 20: 51-70.

Byrd, D. (1993) 54,000 American stops. UCLA Working Papers in Phonetics 83:97-115.

Charette, M. (1990) License to govern. Phonology 7:233-253

Charette, M. (1991a) Conditions on phonological government. Cambridge: Cambridge University Press.

Charette, M. (1991b) Mongolian and Polish meet Government Licensing. SOAS Working Papers in Linguistics and Phonetics 2:275-291

Charette, M. (1998) Empty and pseudo empty categories. SOAS Working Papers in Linguistics and Phonetics 8:167-176.

Chomsky, N. \& Halle, M. (1968) The sound pattern of English. New York: Harper and Row.

Chomsky, N. (1981) Lectures on Government and Binding. Dordecht: Foris Publications.

Chomsky, N. (1982) Some Concepts and Consequences of the Theory of Government and Binding. Cambridge, MA: MIT Press.

Clark, J. \& C. Yallop (1995) An introduction to phonetics and phonology. $2^{\text {nd }}$ edition. Oxford: Blackwell.

Clements, G. (1991) Place of articulation in consonants and vowels: a unified theory. Working Papers of the Cornell Phonetics Laboratory 5:77-123

Cowan, W. \& Rakusan, J. (1985) Source book for linguists. Philadelphia: John Benjamins.

Cruttenden, A. (1994) Gimson's Pronunciation of English. 5th edition. London: Arnold.

Crystal, D. (1987) The Cambridge Encyclopaedia of Language. Cambridge: Cambridge University Press.

Crystal, T. \& House, A. (1987a) Segmental durations in connected speech signals: Current results. Journal of the Acoustical Society of America 83:1553-1573.

Crystal, T. \& House, A. (1987b) Segmental durations in connected speech signals: Syllabic stress. Journal of the Acoustical Society of America 83:1574-1585.

Culicover, P. (1997) Principles and Parameters: An Introduction to Syntactic Theory. Oxford: OUP.

Cutler, A., Dahan, D. \& van Donselaar, W. (1997) Prosody in the comprehension of spoken language: a literature review. Language and Speech 40:141-201.

Cyran, E. (2000) Against licensing of empty nuclei. Handout from talk given at Eötvös Loránd University, Budapest. 


\section{The Phonetics and Phonology of some Syllabic Consonants in Southern British English}

Fidelholtz, J. (1975) Word frequency and vowel reduction in English. Proceedings of CLS 11:200-213.

Fowler, C. (1977) Timing control in speech production. Bloomington: Indiana University Linguistics Club.

Garnes, S. (1976) Quantity in Icelandic: production and perception. Hamburg: Buske Verlag.

Gimson, A. (1989) An introduction to the pronunciation of English. $4^{\text {th }}$ Edition. London: Edward Arnold.

Gussmann, E. (1991) Schwa and syllabic sonorants in a non-linear phonology of English. Anglica Wratislaviensia XVII 1061:25-39.

Gussmann, E. and Cyran, E. (1998) 'Polish consonantal sequences: a phonological testing ground' in Cyran, E. (ed.) Structure and Interpretation Studies in Phonology, pp. 127-137.

Harris, James (1983) Syllable structure and stress in Spanish: A nonlinear analysis. Cambridge, MA: MIT Press.

Harris, John. (1990) 'Segmental complexity and phonological government' Phonology 7.2:255-300.

Harris, J. (1994) English Sound Structure. Oxford: Blackwell.

Harris, J. \& Lindsey, G. (1995) The elements of phonological representation. In Durand, J. \& Katamba F. Frontiers of Phonology: Atoms, structures, derivations. pp 34-79.

Harris, J. \& Lindsey, G. (2000) Vowel patterns in mind and sound. In Noel Burton-Roberts, Philip Carr \& Gerry Docherty (eds.) Phonological knowledge: Conceptual and empirical issues. pp. 185-205.

Hawarth, E. (1994) The trouble with French glides. SOAS Working Papers in Linguistics and Phonetics 4:53-70.

Heo, Y. (1994) Empty Categories and Korean Phonology. PhD. Thesis. School of Oriental and African Studies, University of London, London.

Hubbard, K. (1995) 'Prenasalised consonants' and syllable timing: evidence from Runyambo and Luganda. Phonology 12: 235-256.

Ito, J. (1987) Syllable theory in Prosodic Phonology. PhD Dissertation, University of Massachusetts.

Jensen, S. (1994) Is ? and element? Towards a non-segmental phonology. SOAS Working Papers in Linguistics and Phonetics 4:71-78

Johnson, K. (1997) Acoustic and Auditory Phonetics. Oxford: Blackwell.

Jones, D. (1959) The use of syllabic and non-syllabic $l$ and $n$ in Derivatives of English words ending in syllabic $l$ and $n$. Zeitschrift Für Phonetik 12 (10):249-258.

Kaye, J. (1989) Phonology: A cognitive view. Hillsdale, N.J.: Lawrence Erlbaum.

Kaye, J. (1990a) 'Coda' Licensing. Phonology 7:301-30.

Kaye, J. (1990b) Government in phonology: the case of Moroccan Arabic. The Linguistic Review 6:131-159.

Kaye, J. (1991) 'Do you believe in magic? The story of S + C sequences' SOAS Working Papers in Linguistics and Phonetics 2:293-314.

Kaye, J. (1995) Derivations and interfaces. In J. Durand and F. Katamba (eds.) Frontiers of Phonology. London: Longman. pp.289-332.

Kaye, J., Lowenstamm, J. and Vergnaud, J-R. (1985) The internal structure of phonological representations: a theory of charm and government'. Phonology Yearbook 2:305:28.

Kaye, J., Lowenstamm, J. and Vergnaud, J-R. (1990) Constituent structure and government in phonology. Phonology 7(2): 193-231

Ladefoged, P. \& Maddieson, I. (1996). The sounds of the world's languages. Oxford: Blackwell.

Laver, J. (1994) Principles of phonetics. Cambridge: Cambridge University Press

Lee, H-J (1999) Inter-onset government: its needs and interaction with proper government. SOAS Working Papers in Linguistics 9:253-274.

Lehiste, I. (1964) Acoustical Characteristics of Selected English Consonants. Indiana University Research Center in Anthropology, Folklore and Linguistics 34. Bloomington: Indiana University.

O'Shaughnessy, D. (1981) A study of French vowel and consonant durations. Journal of Phonetics 9:385-406.

Perkell, J., Guenther, F., Lane, H., Matthies, M., Perrier, P., Vick, J. Wilhelms-Tricarico, R., and M. Zandipoor (2000) A Theory of speech motor control and supporting data from speakers with normal hearing and with profound hearing loss. Journal of Phonetics 28:233-272

Ploch. S. (1999) Nasals on my mind. PhD Thesis, School of Oriental and African Studies, University of London, London.

Price, P. (1980) Sonority and syllabicity: acoustic correlates of perception. Phonetica 37: 327-343.

Rietveld, T. \& R. van Hout (1993) Statistical techniques for the study of language and language behaviour. Berlin: Mouton de Gruyter.

Roach, P. (1991) English phonetics and phonology. $2^{\text {nd }}$ Edition. Cambridge: CUP.

Roach, P. (2000) A small encyclopaedia of phonetics. http://www.linguistics.reading.ac.uk/staff/Peter.Roach

Roach, P., Sergeant, P. \& Miller, D. (1992) Syllabic consonants at different speaking rates: A problem for automatic speech recognition. Speech Communication 11: 475-479

Rockey, D. (1973) Phonetic Lexicon. London: Heyden \& Son Ltd.

Rubach, J. (1977) Changes of consonants in English and Polish: a generative account. Prace J zykoznawcze 87:1169

Scheer, T. (1998) Governing Domains are Head Final. In Cyran, E. (Ed.) Structure and Interpretation: Studies in Phonology. Lublin: Folium. pp 261-285) 
Selkirk, E. (1982) The syllable. In H. van der Hulst \& N. Smith (eds.) The structure of phonological representations, vol. 2. Dordecht: Foris Publications. Reprinted in J. Goldsmith (ed.) (1999) Phonological Theory: The essential readings. Oxford: Blackwell.

Spencer, A. (1995) Phonology: theory and description. Oxford: Blackwell.

Sproat, R. \& Fujimura, O. (1993) Allophonic variation in English /1/ and its implications for phonetic implementation. Journal of Phonetics 21: 291-311.

Stevens, K. (1998) Acoustic Phonetics. Cambridge, MA: MIT Press.

Umeda, N. (1976) Consonant duration in American English. Journal of Acoustical Society of America 61,3:846-858.

Wells. J. (1982) Accents of English (3 volumes). Cambridge: Cambridge University Press.

Wells, J. (1995) New syllabic consonants in English. In J. Windsor Lewis (ed.) Studies in General and English Phonetics. London: Routledge. pp 401-412.

Wells, J. (2000) Longman pronunciation dictionary. $2^{\text {nd }}$ edition. Harlow: Longman.

Williams, G. (1997) A pattern recognition model for the phonetic interpretation of elements. SOAS Working Papers in Linguistics and Phonetics 7:275-297.

Woods, A., Fletcher, P. \& A. Hughes (1986) Statistics in language studies. Cambridge: CUP.

www.praat.org 